\title{
Horizontal Mergers and Divestment Dynamics in a Sunset Industry*
}

\author{
Masato Nishiwaki ${ }^{\dagger}$ \\ First version:April 2007 This version:June 2010
}

\begin{abstract}
In oligopolistic industries, the amount of capital investment is likely to be excessive due to the presence of a business-stealing effect and fixed costs. Similarly, sunset industries with declining demand tend to be riddled with chronic excess capital. The reason is that firms will attempt to free-ride on the reduction of industry supply expected from someone else's divestment, hoping to steal their business. This paper highlights the potential of mergers to internalize this business-stealing effect and thereby promote divestment. Using the case of mergers in the Japanese cement industry, it examines whether such merger-induced divestment improve total welfare. A dynamic model of divestment based on the Markov-perfect equilibrium framework of Ericson and Pakes (1995) is estimated using recently developed econometric methods. Then, a counterfactual experiment is conducted to quantify the welfare impact of mergers. The findings suggests that merged firms indeed more actively closed facilities and that, as a result of these mergers, total welfare improved despite a reduction in the consumer surplus.
\end{abstract}

JEL Classification: L13, L41, L61

Keywords: dynamic discrete game, divestment dynamics, horizontal mergers, sunset industry, cement industry

*I am grateful to Hiroyuki Odagiri for his constant support and encouragement. Discussions with Hidehiko Ichimura and Tetsushi Murao have been invaluable. I also have benefited from the comments of many individuals in the course of this study, among them Reiko Aoki, Rieko Ishii, Ryo Kambayashi, Daiji Kawaguchi, Hiroshi Ohashi, Ayako Suzuki and Noriyuki Yanagawa. The research has benefited from the financial support of a grant-in-aid (the 21st Century Center of Excellence Project on the Normative Evaluation and Social Choice of Contemporary Economic Systems) from the Ministry of Education and Science, Japan. All errors remain, of course, my own responsibility.

${ }^{\dagger}$ National Graduate Institute for Policy Studies (GRIPS). Email:mstnishi@gmail.com. 


\section{Introduction}

In so-called sunset industries that face declining demand, an important concern is how firms can reduce their capital stock to remain profitable. From an industry viewpoint, eliminating production or distribution facilities would be beneficial, since it would remove excess capital stock and thereby resulting in savings of the fixed costs associated with operating these facilities such as labor and land.

Yet, in oligopolistic industries such divestment may not take place voluntarily. The reason is similar to the excess entry theorem discussed by Mankiw and Whinston (1986) and Suzumura and Kiyono (1987). The theorem suggests that in oligopolies the presence of a business-stealing effect and fixed costs result in an excessive number of entrants: entrants gain sufficient demand partly by stealing business from incumbent firms. While this is a gain to the entrants, it is not to the industry and, in consequence, such entry is (socially) excessive.

This implies that there is a tendency to invest in capital more in oligopolies than the industry as a whole would want. A firm wants to have capital up to a level where the marginal revenue from the next unit of capital just equals fixed costs. However, in oligopolies, part of that marginal revenue comes from the profits of competitors. This marginal revenue represents a gain only to the firm, not to other firms in the industry, and the total amount of capital stock as a result will be excessive at least from the viewpoint of producers.

In sunset industries, scrapping of capital stock may not take place for exactly the opposite reason: each firm is unwilling to divest because part of the business it abandons by scrapping is captured by its competitors. In other words, every firm intends to freeride on the reduction of industry supply expected from someone else's divestment. The end result is that no firm will divest even though this would reduce fixed costs, thus prolonging the situation where there is excess capital stock.

However, the picture changes if two firms were to merge. A merger would resolve 
the "deadlock" partly by internalizing the business-stealing effect. In a horizontal merger between firms A and B, post-merger, A should have less incentive to maintain the same level of capital as before the merger because the stealing of business from $\mathrm{B}$ is now internalized and brings no gain to the merged firm. Therefore, mergers can promote divestment, providing fixed cost savings. ${ }^{1}$ In fact, it is often observed that firms after a merger rationalize their capital stock.

However, merged firms do not usually consider maximizing total welfare when deciding the level of capital stock. Rather, they will reduce capital stock if the fixed costs plus the sell-off value exceed marginal revenue without considering the effects of divestment on the consumer surplus as well as other firms' profits. Thus, the adjustment of capital following a merger does not necessarily give rise to a higher level of total welfare. From the viewpoint of total welfare, the problem is whether the efficiency gains from mergers, e.g., the fixed cost savings and traditional synergy effects, are greater than the negative effect on the consumer surplus. This implies that whether mergers with capital rationalization improve total welfare is an empirical question that depends on the magnitude of the various effects. The purpose of this study is to conduct just such an empirical investigation, using the cement industry in Japan as a case study.

The Japanese cement industry provides a good case study for examining the welfare effect of mergers in a period of industry decline. Japan's cement industry can be regarded as a sunset industry in the sense that it has faced a prolonged downward trend in demand. Following the bursting of the bubble economy Japan experienced in the 1980s, public and private investment in construction, which is a good indicator of cement demand, decreased substantially during the 1990s and in recent years has settled at about the same level as that seen 30 years ago. As demand shrank, the industry was forced to contract in size and to become more efficient to survive in such

\footnotetext{
${ }^{1}$ Focusing on investment rather than divestment, Berry and Pakes (1993) investigated this effect of mergers on incentives for investment using a dynamic oligopoly model. They showed that a merger internalizes the effect of capacity expansion on the market price and that, in consequence, a merged firm has less incentive to engage in a capacity expansion race.
} 
severe circumstances. Around the mid-point of this phase of decline in the mid-1990s, four mergers and one acquisition took place. Following the mergers, physical capital in the industry, e.g., production and distribution facilities, contracted along with the decline in demand. Whether this consolidation-induced contraction enhanced efficiency in the industry and improved welfare is the main point of interest in this study.

To evaluate the welfare effect of horizontal mergers, a theoretical model to capture the industry dynamics - namely the downward trend in demand and divestment of cement distribution facilities - is constructed, building on the Markov-perfect equilibrium framework of Ericson and Pakes (1995). ${ }^{2}$ The underlying parameters of the model governing divestment dynamics are estimated using the recently developed twostep algorithm of Bajari, Benkard and Levin (2007). With the parameter estimates thus obtained, a counterfactual experiment is then conducted to evaluate the welfare effect of the mergers.

The contribution of this study is twofold. First, since the early works by Ghemawat and Nalebuff (1985, 1990), Fudenberg and Tirole (1986), and Whinston (1988), surprisingly few studies have been made on declining industries, despite the fact that almost all developed nations have declining sectors and how to promote capacity reduction in such sectors is a pressing policy issue. This paper will provide new empirical findings on industry contraction, with a particular emphasis on the role of mergers. Second, the study examines horizontal mergers from a dynamic perspective. The importance of modeling how a merger affects a firm's incentives for investment, entry and exit was first emphasized by Stigler (1968). Since then, and more recently, a number of theoretical models have been proposed, including Berry and Pakes (1993), Gowrisankaran (1999), Pesendorfer (2005) and Choeng and Judd (2006). However, despite the blossoming of the theoretical literature, only very few empirical studies on mergers from a

\footnotetext{
${ }^{2}$ In recent years, the Ericson and Pakes model has been used extensively in both theoretical and empirical studies in the field of industrial organization. An excellent survey is provided by Doraszelski and Pakes (2006).
} 
dynamic perspective have been conducted. To the best of my knowledge, the present paper is one of the first attempts to examine empirically the implications of mergers by employing a fully dynamic model. ${ }^{3}$

The remainder of the paper is organized as follows. Section 2 provides a brief overview of the Japanese cement industry, while Section 3 explains the data used in this paper. Next, Section 4 presents a theoretical model describing the competition in the cement industry. It allows for capital divestment as well as traditional quantity setting competition, building on the Markov-perfect equilibrium framework of Ericson and Pakes (1995). Section 5 presents the empirical procedure. The structural parameters of the model are estimated using the econometric method recently developed by Bajari, Bankard and Levin (2007). Section 6 provides the estimation results. This is followed, In Section 7, by a simulation experiment to evaluate the effect of the mergers in the Japanese cement industry on total welfare. By solving the model in both actual and counterfactual environments with the estimated parameters of the model, it is examined whether the mergers promoted divestment and total welfare was improved. Section 8 concludes.

\section{The Cement Industry in Japan}

This section provides a brief overview of trends in Japan's cement industry, the cement distribution process, the mergers that took place in the mid-1990s, and the effect of these mergers on regional markets.

\footnotetext{
${ }^{3}$ Pesendorfer (2003) developed a simple investment model reflecting competition in the US paper industry. While his model is inherently static, it succeeds in capturing the dynamic aspects of investment decisions in the industry. Recently, Myojo and Ohashi (2008) investigated a merger in the Japanese steel industry using a dynamic investment model.
} 


\subsection{Trends in the Japanese Cement Industry}

The Japanese cement industry provides a good case study for examining the welfare effect of mergers in a period of industry decline. Figure 1 depicts the trends in cement consumption and government and private investment in construction. Cement is the key ingredient of concrete, which is used as construction material for skyscrapers, roadways, railways, airports, seaports and other infrastructure. Cement consumption thus mainly depends on the amount of construction investment in the private and public sectors, as can be seen in Figure 1. Cement consumption in Japan increased steadily from the 1980s and expanded until the bursting of the bubble economy. Since then, it has declined substantially as construction investment shrank, although in recent years cement consumption appears to have stabilized at a level of around $70 \%$ of its peak and the same level as 30 years ago.

As demand shrank, the cement industry began to contract. Figure 2 shows the remarkable reduction in the number of cement distribution facilities during the period. Distribution facilities, called "service stations," connect cement plants with local customers and as such play a key role in the cement supply chain in Japan. Once cement is produced in a plant, it is typically delivered by ship to service stations in regional markets. ${ }^{4}$ Cement service stations are located mainly along the coast and have silos for cement storage. Within an individual region, a cement firm carries its product from its service stations to local consumers by truck. This stage of the transportation from service stations to consumers is called "secondary-stage delivery," whereas transportation from plants to service stations is "primary-stage delivery." The transportation costs of the secondary stage are sufficiently high to prevent firms from delivering their product to customers far from a service station. To avoid long-haul carriage, cement

\footnotetext{
${ }^{4}$ Cement plants tend to be located where there are abundant reserves of limestone. This means that in Japan, the Chugoku, Hokkaido and Kyushu areas account for an overwhelming proportion of cement production. As explained in a later section, there are 11 regional markets in Japan. Cement firms conduct business in some or all of these regions and have local headquarters in the regions.
} 
firms set up several service stations within a regional market, and the number of service stations a firm has in a market, through its effect on transportation costs, is an important determinant of the firm's supply quantity. ${ }^{5}$

The more service stations a firm has, the more it can supply. At the same time, though, operating a service station also involves considerable variable and fixed costs. Such costs include, for example, the cost of maintaining a fleet of cement trucks for deliveries, primary-stage delivery costs, which depend on the number of service stations, and labor costs for the operation of the service station. Thus, when demand declined, pressure for a reduction in the number of service stations arose. In fact, the need to eliminate service stations surplus to requirement in order to restore profitability was one of the key drivers underlying consolidation of the cement industry.

\section{$2.2 \quad$ Mergers}

In the 1990s, faced with shrinking demand, the Japanese cement industry experienced a number of mergers which accelerated market consolidation. Table 1 presents a list of mergers during this period. All of the mergers except Mitsubishi Cement Corp.'s acquisition of Tohoku-Kaihatsu Corp. changed market structure in at least one regional market, and the two mergers in 1998 in fact affected all regional markets by reducing the number of operating firms in all regional markets. ${ }^{6}$

Table 2 shows that as a result of the mergers, the number of firms operating in a particular region fell from an average of roughly nine to about six. Not only did the mergers reduce the number of firms, they also changed the concentration ratio

\footnotetext{
${ }^{5}$ In addition to customers' concrete plants, cement firms deliver their product also to customers' construction sites. This means that they face uncertainty with regard to the distance from their service stations to construction sites. Because of this nature of cement delivery, it is likely to be advantageous for firms to have several distribution facilities in a regional market.

${ }^{6}$ In this context, it should be noted that Ube-Mitsubishi Cement Corp. started as a firm that initially only merged the sales and distribution divisions of Ube Cement Corp. and Mitsubishi Cement Corp. in 1998 and combined all other divisions in 2000. This paper deals with Ube-Mitsubishi Cement Corp. as a merged firm during the entire observation period because the focus is on cement firms' supply behavior in a regional market.
} 
accordingly, as is revealed in Table 3. This shows that the three-firm concentration ratio (CR3) in terms of the number of service stations rose nearly 15 percentage points following the first round of mergers in 1994 and, on average, exceeded $80 \%$ after the second round of the mergers in 1998.

Price is also an important factor in evaluating the effect of mergers. Figure 3, presenting the trend in cement price from 1991 to 2006, shows that even after the big mergers in 1994 and 1998, the cement industry continued to experience falling prices. While one would usually expect prices to rise in response to a contraction in supply capacity as a result of mergers, what this trend suggests is that the continuing decline in demand more than offset any such effect. Thus, in examining how the mergers influenced prices, it is necessary to take this exogenous trend in demand into account and to separate it from the effect of the mergers.

As mentioned above, a substantial reduction in the number of cement distribution facilities was observed following the mergers. This is shown in Figure 4, which shows the steady decline in the total number of service stations between 1998 and 2006 and, moreover, illustrates that most of the reductions were undertaken by the firms that merged. The merged firms scrapped about $25 \%$ of their service stations during this period compared with only a $15 \%$ reduction in the number of service stations by nonmerged firms. This suggests that the mergers may have affected the firms' incentives for scrapping their service stations and prompted the reduction in the total number of service stations.

The developments described here regarding the decline in demand and the downward trend in the number of service stations indicate that it is important to explicitly consider the constantly changing environment when evaluating the effects of the mergers. Failure to consider the dynamics of the Japanese cement industry arising from endogenous and exogenous factor will result in erroneous conclusions regarding the merger during this period of decline. 


\section{Data}

A key objective of this study is to analyze how the mergers affected the incentive for divesting cement distribution facilities and whether the merger-induced divestment improved total welfare. To this end, data covering the period from 1998 to 2006, that is the period following the merger wave, is used. The data used in this study are collected from the Cement Yearbook(Cement Nenkan in Japanese), which is published annually by Cement Shimbun Co. Ltd, and SNA statistics. The Cement Yearbook provides useful firm-level and regional-level information on, e.g., the number of firms' service stations in an individual regions, and firms' quantity of supply in a region, and regionallevel cement prices. On the other hand, the SNA statistics provide data on the total amount of public and private investment in construction, which is a key determinant of cement demand, and regional GDPs, which can be considered to influence the sell-off value of service stations.

According to the Japan Cement Association, the cement market in Japan is divided into 11 regional markets, consisting of the Hokkaido, Tohoku, Northern and Southern Kanto, Hokuriku, Tokai, Kansai, Chugoku, Shikoku, Kyushu, and Okinawa regions. This study focuses on six of these regional markets: Hokkaido, Tohoku, Tokai, Kinki, Chugoku, and Shikoku. The reason is that for the five other markets, either price information is not available (Hokuriku and Okinawa), the average size of service stations is very different from that of other markets (Southern Kanto and Kysuhu), or both (Northern Kanto). ${ }^{7}$

Summary statistics of the data used in the following sections are provided in Table 4. PRICE is the annual average cement price in an individual regional market, expressed in yen per ton. CEMENT CONSUMPTION is the total amount of annual consumption

\footnotetext{
${ }^{7}$ Specifically, the average size of service stations in Northern Kanto is considerably larger than in the rest of the country, while the number of service stations is very small. On the other hand, in the Kyushu region, the situation is exactly the opposite. While investigating the reasons for these differences is beyond the scope of this study, they imply that the sell-off value of service stations in these regions would be very different from that of service stations in other regions.
} 
in an individual regional market, expressed in tons. CONSTRUCTION INV is the total amount of private and government investment in construction in Japan as a whole and is measured in billion yen. REGIONAL GDP is regional real gross domestic product, in billion yen. SUPPLY QUANTITY is the quantity supplied by a firm in an individual region, expressed in tons. NO.SS is the number of service stations of a firm in an individual region, and DIVESTMENT represents the number of service stations scrapped by a firm in a region.

To ensure the estimation, details of which will be explained later, the analysis focuses on the activities of the largest four or five firms in an individual market. Specifically, the sample consists of five firms for Hokkaido, Tohoku, Kinki, Chugoku and Shikoku, and four firms for Tokai. This means that relatively small firms are excluded from the sample. However, the total amount supplied by these selected large firms accounts for at least $85 \%$ of the total supply in a regional market at any given time, and the average is more than $95 \%$ during the observation period. Therefore, focusing only on the largest firms will not have a substantial impact on the results of the analysis.

\section{Model}

To assess the welfare effect of the mergers, it is necessary to construct a theoretical model that captures the features of the cement industry. ${ }^{8}$ As previously noted, individual cement markets are localized and concentrated, and the product can be regarded as a homogeneous good. Further, the industry has been facing a downward trend in demand and cement firms have been forced to divest cement distribution facilities, service stations (SSs for brevity hereafter), to remain profitable. While selling off some of its SSs allows a cement firm to realize the sell-off value of such facilities and to save fixed

\footnotetext{
${ }^{8}$ The theoretical model does not consider the merger decision itself. This is because a convincing merger model, which can describe the merger decision process in the cement industry well, is difficult to construct. In addition, even if it were possible to develop an endogenous merger model, it would be hard to estimate it given that the number of merger cases in the cement industry is very small.
} 
costs, part of its business will be stolen by competitors unless an SS is completely idle before being scrapped. Thus, strategic interaction between cement firms in a regional market is one of the key determinants of their divestment decisions. In addition, it is natural to assume that scrapping an SS has a dynamic impact on future market configurations: doing so will change not only the number of an individual firm's SSs in the subsequent periods but also the entire state of the market through strategic interaction among firms. As a result, the stream of future cash flows depends on divestment in the current period. Therefore, in deciding whether to scrap SSs, a cement firm will contemplate the influence of its action on the future market structure.

Given these industry characteristics - competition in a homogeneous product market, the dynamic decision regarding divesting SSs and the exogenous demand shift-, a model of oligopolistic competition in a dynamic environment is needed. Ericson and Pakes (1995) provide an elegant dynamic oligopoly framework designed to capture industry dynamics with heterogeneous firms. Building on their Markov-perfect equilibrium framework, a dynamic model of SS divestment is constructed here. ${ }^{9}$

In the model, each firm is characterized by only its state variable, and a regional market is completely described by a state vector consisting of firms' state variables, an industry-wide exogenous demand shifter, and regional economic conditions. At the beginning of each period, firms decide simultaneously whether to scrap any SSs, and if they do so, choose the number of SSs scrapped, given their beliefs regarding future market configurations. Following the divestment decisions, product market competition takes place. Given their SSs, a demand shifter, and their competitors' strategies, firms compete with each other in terms of quantity. At the end of the period, each firm earns a profit as a result of product market competition and receives the sell-off value of SSs sold, which depends on regional economic conditions. The state variables evolve as the divestments are completed and new values regarding demand and regional economic

\footnotetext{
${ }^{9}$ The model can be regarded as a simplified version of the model by Besanko, Doraszelski, Lu and Sattherthwaite (2008), which allows for both investment and divestment actions in dynamic oligopoly.
} 
conditions are realized.

In contrast to the original model of Ericson and Pakes (1995), in which investment is a continuous variable (but the state variables are still discrete), the present analysis has to consider discrete divestment actions because an SS is indivisible. This discrete nature of the divestment behavior may cause an equilibrium existence problem, as Doraszelski and Satterthwaite (2007) point out. To avoid such a problem, the sell-off value of an SS is considered to be a random variable from the sell-off value distribution, and it is assumed that before firms take any actions, they observe the sell-off value for their SS privately. Other than ensuring the existence of an equilibrium, introducing a privately known sell-off value is justified for at least two further reasons. First, in the real world, firms face uncertainty regarding their competitors' actions since they do not have exact knowledge of their competitors' payoffs. Introducing a privately known random sell-off value into the model reflects this uncertainty. The other reason is more practical. A dynamic stochastic game with incomplete information can be estimated using the econometric methods developed recently by Aguirregabiria and Mira (2007), Bajari, Benkard and Levin (2007), Pakes, Ostrovsky and Berry (2007), and Pesendorfer and Schidt-Dengler (2008), and is numerically tractable with the purification technique of Doraszelski and Satterthwaite (2007). With the advancements in the econometrics of dynamic game models and in numerical methods for computing equilibria in dynamic games, the underlying parameters of the model can be recovered from the observed data and, once the underlying parameters are at hand, a counterfactual experiment can be conducted. For these reasons, this study describes the competition in the cement industry as a dynamic discrete game with incomplete information.

States The theoretical model developed here is used to describe the competition between cement firms in a regional market. ${ }^{10}$ There are $N$ cement firms in a region. A

\footnotetext{
${ }^{10}$ Cement firms typically organize their branch network on a regional basis, that is, the local manager of a cement firm is responsible for sales activities in that regional market. It is therefore assumed that local managers decide the supply quantity and make divestment decisions, and these decisions do not
} 
regional cement market is assumed to be completely characterized by payoff-relevant state variables. The list of state variables includes firms' state variable, the exogenous demand shifter, and the level of regional economic activity. The number of a firm's SSs in the region indicates the state variable of the firm. The number of SSs a firm has affects its marginal cost of supply and, consequently, as previously explained, substantially influences its profit. The demand shifter is also payoff-relevant because firms's profits depend on the demand conditions in each period. The level of regional economic activity influences the sell-off value of SSs because it affects the land price in the region. The state vector in period $t$ in a market is defined as

$$
\omega_{t}=\left(s_{1 t}, \ldots, s_{N t}, z_{t}, v_{t}\right)
$$

where state variable $s_{i t}$ represents the number of firm $i$ 's SSs in the regional market at period $t, z_{t}$ is the amount of construction investment in period $t$, which is a key determinant of cement demand, and $v_{t}$ is regional GDP, which influences the sell-off value of SSs in period $t$. The region subscript $r$ is dropped for expositional simplicity.

The important assumption made here is that regional markets are independent of each other. The states of other regional markets thus are not payoff-relevant and hence are not included in the state vector $\omega_{t}$. Other points that are not considered in the model but that potentially influence profits are plant location and production capacity. Plant location affects "primary delivery" transportation costs from the plant to service stations and may influence the firm's profit in the region; therefore, the distance between a plant and each regional market may be a factor influencing profits. In addition, a firm's supply in a regional market may be bounded by the production capacity of its plants and not just by the supply capacity determined by its SSs. However, as previously discussed, the transportation costs of "primary delivery" are relatively

influence the decisions of local managers in other markets. In other words, this assumption means that regional cement markets are mutually independent. 
low and will not have a significant impact on total transportation costs. Moreover, omitting production capacity is also likely to cause no problem, given that the capacity utilization rate was below $80 \%$ on average during the observation period, implying that cement plants - at least on average - did not face any capacity constraints.

The number of a firm's SSs in the next period, $t+1$, depends on whether the firm sells one or more of its SSs, and how many, in the current period, $t$. Changes in a firm's state variable is deterministic, conditional on divestment. That is, if firm $i$ scrapped $d_{i t} \mathrm{SSs}$, then its state variable in the next period, $t+1$, is given by

$$
s_{i t+1}=s_{i t}-d_{i t},
$$

where $s_{i t+1}$ is the number of firm $i$ 's SSs in period $t+1$. This adjustment is assumed to take one year, and depreciation is not considered.

Demand shifter $z_{t}$ moves stochastically to a lower level or remains at the current level. Regional GDP $v_{t}$ also moves stochastically, but it can go to a higher or lower state or remain in the same state. In contrast to the movement of firms' state variables, these factors are assumed to evolve exogenously.

Except for regional GDP $v_{t}$, the movement of the state variables is weakly unidirectional. That is, they can only move to a lower state or remain in the current state, $\omega_{t}$. This reflects the fact that the cement industry faced a downward trend in demand and that cement firms have continued to reduce their number of facilities accordingly. ${ }^{11}$

Timing In the model, firms' actions are all a function of the state variables at the beginning of a period. That is, each firm initially makes a divestment decision given its beliefs with regard to other firms' strategies and with regard to future market

\footnotetext{
${ }^{11}$ The unidirectional movement of state variables is important. A sufficient condition for uniqueness of equilibria in a dynamic stochastic game is that the reaction functions intersect once at every state and movements through the state space are unidirectional (Besanko, Doraszelski, Lu and Satterthwaite 2008). In this model firms' state variable and demand shifter are unidirectional and multiple equilibria is therefore less likely to arise than in models where state variables move freely up and down.
} 
conditions, after observing the current demand shifter and privately knowing the selloff value of its SSs. After all firms have made their divestment decisions, competition in the product market takes place, given the current state variables. At the end of the period, each firm earns the per-period profit from competition in the product market and receives the sell-off value of its SSs if it scrapped any. Then, firms' state variables evolve following firms' divestments and the two exogenous state variables change.

The sequence of events in each period unfolds as follows:

1. Firms know the sell-off values of their SSs privately and observe the current demand shifter.

2. Firms makes their divestment decisions simultaneously.

3. Given the current state variables, $\omega_{t}$, firms compete with each other over quantity.

4. Firms obtain the per-period profits and receive the sell-off values if they sold off SSs.

5. The state variables evolve as the divestments are completed and new values of the exogenous variables, construction investment and regional GDP, are realized.

Cash flow The per-period cash flow of firm $i$ at state $\omega_{t}$ is composed of two terms: profits from the product market competition and the proceeds of any divestments. Thus, the per-period cash flow of firm $i$ at state $\omega_{t}$ can be written as

$$
\pi_{i}\left(\omega_{t}, \phi_{i t}\right)=u_{i}\left(s_{i t}, s_{-i t}, z_{t}\right)+\phi_{i t} d_{i t}
$$

$u_{i}\left(s_{i t}, s_{-i t}, z_{t}\right)$ denotes firm $i$ 's profit from the product market, given its own state $s_{i t}$, the other firms' state $s_{-i t}$, and demand shifter $z_{t} . \phi_{i t}$ is the realized sell-off value of firm $i$ 's SS at period $t$. It is assumed that this can be written as

$$
\phi_{i t}=\mu v_{t}+\left(k v_{t}\right) \nu_{i t}
$$


where $\nu_{i t}$ is a random variable drawn from the standard normal distribution and is independent across firms and time periods. This specification means that the mean and variance of the sell-off value distribution depend on the state variable $v_{t}$, which represents the regional GDP level. That is, a sell-off value is assumed to be a random variable drawn from a normal distribution with mean $\mu v_{t}$ and variance $\left(k v_{t}\right)^{2}$.

Product Market Competition and Profits Given the current state, $\omega_{t}$, firms compete with each other for quantity in the product market. The product market profit of firm $i$ at state $\left(s_{i t}, s_{-i t}, z_{t}\right)$ is written as follows:

$$
u_{i}\left(s_{i t}, s_{-i t}, z_{t}\right)=P\left(Q_{t}\right) q_{i t}-C\left(s_{i t}, q_{i t}\right)
$$

where $P\left(Q_{t}\right)$ is the inverse demand function, $C\left(s_{i t}, q_{i t}\right)$ is the cost function depending on the state variable, $s_{i t}$, and the quantity supplied by firm $i$ in that period, $q_{i t}$. An inverse demand function with constant price elasticity is assumed:

$$
P\left(Q_{t}\right)=A_{0} Q_{t}^{\alpha_{1}} z_{t}^{\alpha_{2}}
$$

where $A_{0}$ is a time-invariant region-specific effect on price.

As explained previously, the important cost factors are transportation costs, which are influenced by the number of SSs a firm has in a market, and the fixed costs of maintaining an SS. Thus, the cost function is expressed as a function of firm $i$ 's own state variable, $s_{i t}$, quantity, $q_{i t}$, and fixed cost, $f_{s s}$, as follows:

$$
C\left(s_{i t}, q_{i t}\right)=A_{3} s_{i t}^{\alpha_{4}} q_{i t}+f_{s s} s_{i t}
$$

where $A_{3}$ is a region-specific effect and is assumed to be constant over time. If $\alpha_{4}$ is negative (and, in fact, it is estimated to be negative in a later section), marginal costs can decrease with the number of SSs a firm has. The lower marginal costs can 
be achieved mainly by better management of distribution across several SSs, since costly long-haul transportation can be avoided. Fixed costs $f_{s s}$ are the flow costs of maintaining an SS, which include the costs of the minimum labor input and of the equipment required to operate an SS, such as a fleet of cement delivery trucks. It is assumed that fixed costs $f_{\text {ss }}$ are common to all firms in all regions and constant over time.

A Cournot-Nash equilibrium in the product market is assumed. For computational and empirical tractability, it is also assumed that the quantities set in the product market do not have any dynamic effect. This assumption is the so-called 'staticdynamic' breakdown, which means that quantities supplied in the current period do not affect any actions in the following periods. Due to this 'static-dynamic' breakdown, the per-period profit $u_{i}\left(\omega_{t}\right)$ can be computed off the algorithm for computing the equilibria of this dynamic divestment model. ${ }^{12}$

Value Functions and Divestment Decisions Next, the decision process regarding scrapping cement distribution facilities is considered. As a firm's divestment decision in a period affects market structure in the subsequent periods, it can change the stream of its future cash flows. It is natural to assume that firms' divestment decision is dynamic in nature and, thus, each firm makes its divestment decision to maximize expected future cash flows, given its beliefs regarding competitors' actions and future market conditions.

To analyze the dynamic decision problem in such a complex environment, following Maskin and Tirole (2001), attention here focuses on pure Markov strategies. In Markov strategies, the past influences current actions only through its effect on the current state variables, which summarize the direct effect of the past actions on the current state. Formally, a Markov strategy, which maps state variables and a private shock into

\footnotetext{
${ }^{12}$ In other words, per-period profits can be treated as primitives of the model when computing equilibria.
} 
actions is expressed as $d_{i}=d\left(\omega, \phi_{i}\right), d_{i} \in D_{i}$. In this model, an action is divestment, and $d_{i}$ indicates the number of SSs firm $i$ scraps and is a discrete variable, owing to the indivisible nature of SSs.

Firm $i$ 's decision problem is to choose the number of its SSs to scrap in the current period, taking into consideration the effect on the future cash flow stream, given its belief regarding future market configurations. Then, the value function of firm $i$ at state $\omega$ is defined recursively by the solution to the following Bellman equation:

$$
\begin{aligned}
V_{i}\left(\omega, \phi_{i}\right)= & \max _{d_{i} \in D_{i}}\left\{u_{i}\left(s_{i}, s_{-i}, z\right)+d_{i} \phi_{i}\right. \\
& \left.+\beta \sum_{s_{-i}^{\prime},\left(z^{\prime}, v^{\prime}\right)} V_{i}\left(s_{i}-d_{i}, s_{-i}^{\prime}, z^{\prime}, v^{\prime}\right) g_{i}\left(s_{-i}^{\prime}, s_{i}, s_{-i}, z, v\right) q\left(z^{\prime}, v^{\prime} \mid z, v\right)\right\},
\end{aligned}
$$

where $\beta$ is the discount factor, and the summation is taken over the one-period reachable states of other firms, $s_{-i}^{\prime}$, and over the period of demand shifter $z^{\prime} . V_{i}\left(s_{i}^{\prime}, s_{-i}^{\prime}, z^{\prime}, v^{\prime}\right)$ is firm $i$ 's expected value function at state $\omega$ before observing the sell-off value of the SSs it has, and is defined as $V_{i}\left(s_{i}^{\prime}, s_{-i}^{\prime}, z^{\prime}, v^{\prime}\right)=\int V_{i}\left(s_{i}-d_{i}, s_{-i}^{\prime}, z^{\prime}, v^{\prime}, \phi_{i}^{\prime}\right) d F\left(\phi_{i}^{\prime} ; \mu v^{\prime},\left(k v^{\prime}\right)^{2}\right)$. For expositional convenience, the components of the state vector, $\left(s_{i}, s_{-i}, z, v\right)$, are explicitly expressed. $g_{i}\left(s_{-i}^{\prime}, s_{i}, s_{-i}, z, v\right)$ is firm $i$ 's perceived transition probabilities of the competitors' current state, $s_{-i}$, to the next state of it, $s_{-i}^{\prime}$. This can be written as the product of firm $i$ 's beliefs regarding its competitors' actions $d_{-i}$ at state $\omega$ :

$$
g_{i}\left(s_{-i}^{\prime}, s_{i}, s_{-i}, z, v\right)=\prod_{-i} \sigma_{i}\left(d_{-i} \mid s_{i}, s_{-i}, z, v\right)
$$

where $s_{-i}^{\prime}=s_{-i}-d_{-i} \cdot q\left(z^{\prime}, v^{\prime} \mid z, v\right)$ is the transition probability of the current demand shifter $z$ and the regional GDP $v$ to the next state, $z^{\prime}$ and $v^{\prime}$.

To express the optimal divestment decision rule, let $W_{i}\left(d_{i} \mid \omega\right)$ be the weighted average of the expected value functions when firm $i$ takes action $d_{i}$ at the current state 


$$
W_{i}\left(d_{i} \mid \omega\right)=\beta \sum_{s_{-i}^{\prime},\left(z^{\prime}, v^{\prime}\right)} V_{i}\left(s_{i}-d_{i}, s_{-i}^{\prime}, z^{\prime}, v^{\prime}\right) g_{i}\left(s_{-i}^{\prime}, d_{-i}, s_{i}, s_{-i}, z, v\right) q\left(z^{\prime}, v^{\prime} \mid z, v\right) .
$$

At the beginning of each period, firm $i$ knows the sell-off value of its SSs privately, and it chooses the number of SSs to be scrapped in that period by comparing the sell-off value with the differentials in the future expected value functions resulting from divestment. This optimal decision problem is expressed in the following way:

$$
d_{i}=\left\{\begin{array}{l}
0 \text { if } W_{i}(0 \mid \omega)-W_{i}(1 \mid \omega) \geq \phi_{i} \\
a(1 \leq a<\bar{a}) \text { if } W_{i}(a-1 \mid \omega)-W_{i}(a \mid \omega)<\phi_{i} \leq W_{i}(a \mid \omega)-W_{i}(a+1 \mid \omega) \\
\bar{a} \quad \text { if } W_{i}(\bar{a} \mid \omega)-W_{i}(\bar{a}-1 \mid \omega)>\phi_{i} .
\end{array}\right.
$$

The difference between the $W_{i}(\cdot \mid \omega)$ s denotes the cutoff point and $\bar{a}$ is the maximum number of SSs to be scrapped. If firm $i$ receives a sell-off value below the first cutoff point, it does not do anything and stays in $s_{i}$ in the next period. Otherwise, divestment occurs according to the above decision rule (11). For example, if the sell-off value of firm $i$ 's SSs is beyond the first cutoff point but not above the second point, it divests only one SS. Alternatively, if it falls between the second and the third cutoff point, firm $i$ scraps two SSs. Thus, the divestment decision rule is expressed in terms of the cutoff strategy depending on the private sell-off value and the expected value function differentials.

Alternatively, the cutoff decision rule can be expressed in terms of the probability that each action is taken. Let $P_{i}\left(d_{i} \mid \omega\right)$ be the probability that firm $i$ divests $d_{i}$ SSs in 
state $\omega$ :

$$
P_{i}\left(d_{i} \mid \omega\right)=\left\{\begin{array}{l}
\int_{-\infty}^{W_{i}(0 \mid \omega)-W_{i}(1 \mid \omega)} d F\left(\phi_{i} ; \mu v,(k v)^{2}\right) \text { if } d_{i}=0 \\
\int_{W_{i}\left(d_{i}-1 \mid \omega\right)-W_{i}\left(d_{i} \mid \omega\right)}^{W_{i}\left(d_{i} \mid \omega\right)-W_{i}\left(d_{i}+1 \mid \omega\right)} d F\left(\phi_{i} ; \mu v,(k v)^{2}\right) \text { if } 1 \leq d_{i}<\bar{a} \\
\int_{W_{i}\left(d_{i} \mid \omega\right)-W_{i}\left(d_{i}-1 \mid \omega\right)}^{\infty} d F\left(\phi_{i} ; \mu v,(k v)^{2}\right) \text { if } d_{i}=\bar{a} .
\end{array}\right.
$$

The last remaining component of the model is the expected value function $V_{i}\left(s_{i}, s_{-i}, z\right)$. This can be obtained by integrating over $\phi_{i}$ on both sides of (8):

$$
\begin{aligned}
V_{i}(\omega)= & u_{i}\left(s_{i}, s_{-i}, z\right) \\
& +\sum_{d_{i}} P\left(d_{i} \mid s_{i}, s_{-i}, z, v\right)\left\{d_{i} E\left[\phi_{i} \mid s_{i}, s_{-i}, z, v, d_{i}\right]+\beta W_{i}\left(d_{i} \mid s_{i}, s_{-i}, z, v\right)\right\}(13)
\end{aligned}
$$

$E\left[\phi_{i} \mid \omega, d_{i}\right]$ is the expectation of the sell-off value conditional on scrapping $d_{i}$ SSs. $^{13}$ Once the expected value functions are at hand, firm $i$ 's optimal choice can be obtained by (11) or (12).

The continuous state variable $\phi_{i}$ is eliminated from the state variables vector by integrating it out. Expression (13) is very useful because the computational disadvantage created by the introduction of private information disappears and the equilibria are computable.

Equilibrium To analyze equilibrium divestment behavior, attention is restricted to symmetric Markov-perfect Nash equilibria (MPE) because the model of product market competition developed here gives rise to symmetric profit functions. An MPE ensures that at each state, each firm chooses an optimal action given its beliefs regarding

${ }^{13}$ The expected sell-off value equals $\mu_{1} v+k v E\left[\nu_{i} \mid \omega, d_{i}\right]$, and $E\left[\nu_{i} \mid \omega, d_{i}\right]$ is calculated by

$$
E\left[\nu_{i} \mid \omega, d_{i}\right]=\left\{\begin{array}{l}
{\left[P_{i}\left(d_{i} \mid \omega\right)\right]^{-1} \int \nu_{i} \cdot \mathbf{1}\left[\frac{W_{d_{i}-1}-W_{d_{i}}-\mu v}{k v}<\nu_{i} \leq \frac{W_{d_{i}}-W_{d_{i}+1}-\mu v}{k v}\right] d \Phi\left(\nu_{i}\right) \text { if } 0<d_{i}<\bar{a}} \\
{\left[P_{i}\left(d_{i} \mid \omega\right)\right]^{-1} \int \nu_{i} \cdot \mathbf{1}\left[\frac{W_{d_{i}}-W_{d_{i}-1}-\mu v}{k v}<\nu_{i}\right] d \Phi\left(\nu_{i}\right) \text { if } d_{i}=\bar{a}}
\end{array}\right.
$$

where $W_{d_{i}}$ is $W_{i}\left(d_{i} \mid \omega\right)$. 
the future market structure, and those beliefs are consistent with the actions of other competitors. The divestment strategy profile $\mathbf{d}^{*}$ is an MPE if, for all firm $i$ 's states $\omega$ and strategies $d_{i}^{\prime}$,

$$
V_{i}\left(\omega ; \mathbf{d}^{*}\right) \geq V_{i}\left(\omega ; d_{i}^{\prime}, \mathbf{d}_{-i}^{*}\right)
$$

The existence of the MPE follows from the arguments in Doraszelski and Satterthwaite (2007).

\section{Estimation}

The aim of this section is to estimate the underlying parameters governing the dynamics in the theoretical model. Target parameters can be divided into two types: static parameters and dynamic parameters. Static parameters govern static competition and determine per-period profits. These parameters, including the parameters of demand and cost functions, can be recovered without any difficulty by standard estimation techniques. On the other hand, as the dynamic parameters have to be inferred from firms' dynamic decision processes, estimation of these parameters, involving computing value functions, is computationally challenging. In particular, computing value functions in IO models is extremely burdensome, in terms of computation time, because it has to deal with strategic interaction among players. Therefore, although the standard estimation algorithms proposed by Rust (1987) and Pakes (1986), which require computing fixed points that determine value functions at different trial parameter values, can be applied to single-agent dynamic decision problems, they are usually infeasible in multiple-agent settings. ${ }^{14}$

\footnotetext{
${ }^{14}$ There is another reason that the nested fixed point approach cannot be applied straightforwardly to the estimation of game theoretic models. The presence of multiple equilibria makes the econometric model of a game incomplete. That is, due to the presence of multiple equilibria, the estimation strategy, which searches for the parameter values that make the behavior implied by the economic model fit as close as possible to the observed behavior, cannot work because the relationship between the behavior
} 
However, in recent years, innovative econometric techniques have been developed that can resolve the computational problem in estimating models of multiple agents' dynamic decision problems (see, e.g., Aguirregabiria and Mira 2007; Bajari, Benkard and Levin 2007; Pakes, Ostrovsky and Berry 2007; and Pesendorfer and SchmidtDengler 2008). ${ }^{15}$ These techniques can avoid or mitigate the time-consuming value function computations by applying to dynamic games a novel two-step estimator for the single-agent dynamic decision process of Hotz and Miller (1993). In this paper, to estimate the structural parameters, the simulation estimator proposed by Bajari, Benkard and Levin (2007; hereafter BBL) is used. The basic procedure of the estimation involves the following two steps: (1) Under the assumptions that the observed data are generated from a single MPE profile and that the equilibrium selection mechanism is the same across all regional markets, the equilibrium policy functions and the transition probabilities as well as the profit functions are estimated, and the equilibrium value functions are approximated by averaging many simulated paths generated by the estimated policy functions and transition probabilities. ${ }^{16}$ (2) The parameters of interest are set to satisfy the equilibrium conditions under which the value functions resulting from equilibrium strategies dominate the alternative value functions resulting from nonequilibrium strategies.

Let $V_{i}(\omega \mid \mathbf{d}(\omega, \phi) ; \theta)$ be the expected value function of firm $i$ at state $\omega$ under the parameter values of $\theta$, assuming firm $i$ is following the Markov strategy $d_{i}$ and rival firms are following strategy $\mathbf{d}_{-i}$. Then, the expected value function can be defined as

implied by the model and the observed behavior is not one-to-one.

${ }^{15}$ Using these recently developed techniques, Ryan (2006) examines the effect of an environmental regulation on cement producing plants in the US in a dynamic framework, while Collard-Wexler (2006), investigating entry and exit decisions in the US ready-mix concrete industry, analyze how demand fluctuations influence the market structure.

${ }^{16}$ See Berry and Tamer (2006) for a detailed discussion on the issues of multiple equilibria and equilibrium selection mechanisms as well as their critique of the common equilibrium assumption across different markets. 
the sum of the future values of cash flows $\pi_{i}\left(\omega_{t}, \mathbf{d}\left(\omega_{t}, \phi_{t}\right), \phi_{i t} ; \theta\right)$ from starting state $\omega$ :

$$
V_{i}(\omega ; \mathbf{d}(\omega, \phi), \theta)=E\left[\sum_{t=0}^{\infty} \beta^{t} \pi_{i}\left(\omega_{t}, \mathbf{d}\left(\omega_{t}, \phi_{t}\right), \phi_{i t} ; \theta\right) \mid \omega_{0}=\omega ; \theta\right]
$$

The expectation is taken over the current and future private values $\phi_{t}$ and future states $\omega_{t}$. Forward simulation approximates the above expected value function $V_{i}$ by averaging many simulated paths of infinite future cash flow streams starting from $\omega$. As will be explained, the optimal choice rule of firm $i$ at state $\omega$ can be expressed by a function of the choice probabilities $\mathbf{P}_{i}(\omega)=\left(P_{i}(0 \mid \omega), P_{i}(1 \mid \omega), \ldots, P_{i}(\bar{a} \mid \omega)\right)$, and therefore, value function $V_{i}$ is also a function of the choice probabilities. By the definition of MPE, the equilibrium value functions must be greater than or equal to the value functions resulting from the alternative, nonequilibrium play $d_{i}^{\prime}\left(\omega, \phi_{i}\right)$. Therefore, the following equilibrium condition should be satisfied at the vector of true parameter values $\theta_{0}$ :

$$
V_{i}\left(\omega ; \mathbf{d}^{*}(\omega, \phi), \theta_{0}\right) \geq V_{i}\left(\omega ; d_{i}^{\prime}\left(\omega, \phi_{i}\right), \mathbf{d}_{-i}^{*}\left(\omega, \phi_{-i}\right), \theta_{0}\right)
$$

\subsection{First-step Estimation}

In the first step, the demand function and the cost function are estimated to obtain the parameters governing the quantity competition, and the per-period profits are obtained. Then, the equilibrium policy functions can be estimated from the observed equilibrium plays at each state. With these estimates, the equilibrium value functions can be calculated by averaging many simulated equilibrium paths.

Demand Function The following log-linear demand function is estimated:

$$
\ln \left(Q_{r t}\right)=\alpha_{0}-\alpha_{1} \ln \left(P_{r t}\right)+\alpha_{2} \ln \left(z_{t}\right)+\epsilon_{r t},
$$


where $P_{r t}$ is the price at time $t$ in a region $r, Q_{r t}$ is the market quantity, and $z_{t}$ is the total amount of private and public construction spending. The parameters of the demand function are estimated using two-stage least squares (2SLS). Instruments are one-period lagged endogenous variables.

Cost Function As cost-side variables are proprietary to firms and inherently difficult to obtain, straightforward estimation as in the case of the demand function is not possible. Therefore, to estimate the cost function, an assumption regarding the product market competition has to be imposed. ${ }^{17}$ The equilibrium concept used here is that of a Cournot-Nash equilibrium. In a Cournot game, each firm determines its quantity to maximize the per-period profit function, given other firms' quantities. Firm $i$ 's predicted marginal cost is derived from the first-order condition of the firm's profit maximization problem,

$$
m c_{i r t}=P_{t}\left(Q_{r t}\right)+\frac{\partial P\left(Q_{r t}\right)}{\partial q_{i r t}} q_{i r t}
$$

With the estimated demand function, the marginal cost can be easily calculated. Then, as if it were observed, the marginal cost function, which is assumed to depend on the number of SSs, $s_{i r t}$, can be estimated by OLS. Using a logarithmic specification, the marginal cost of firm $i$ is written as

$$
\ln \left(\hat{m} c_{i r t}\right)=\alpha_{3}+\alpha_{4} \ln \left(s_{i r t}\right)+\epsilon_{\text {irt }}
$$

Unobservable cost shocks $\epsilon_{\text {irt }}$ are assumed to be independently and identically distributed (i.i.d) and are not considered as a state variable here for simplicity. Market-

\footnotetext{
${ }^{17}$ Estimating cost function parameters by imposing an assumption regarding equilibrium behavior is based on Berry, Levinsohn and Pakes (1995). Recently, Rosen (2007) proposed an alternative approach where no equilibrium assumption is imposed. By applying the concept of partial identification, he placed bounds to estimate marginal costs. While such an approach is quite interesting, it is not pursued here.
} 
specific effects on the marginal cost are included.

Before proceeding to the estimation of the equilibrium policy functions, a clear drawback in this estimation approach should be noted. Fixed cost $f_{\text {ss }}$ cannot be identified in this step because it is dropped from the first-order conditions. Unfortunately, data on the minimum flow cost required for the annual maintenance of an SS were unavailable. Therefore, as explained in a later section, fixed costs are estimated in the second step.

Divestment Policy Functions The last empirical object in the first step is to estimate the equilibrium policy functions governing divestment behavior. The theoretical model suggests that the equilibrium policy functions should be a function of the current state variables and a random sell-off value. The divestment decision strategy is a cutoff strategy because of the indivisible nature of an SS. The cutoff strategy means that the policy functions are weakly increasing in $\phi_{i}$ rather than strictly increasing. Furthermore, in the model here, the sell-off value distribution is allowed to vary according to regional economic conditions.

The weakly increasing policy function and the time-variant sell-off value distribution do not allow the straightforward application of the method of BBL (2007). Therefore, their approach is slightly modified to estimate the divestment policy functions. This modified approach proceeds by first estimating from the data the choice probabilities of all possible actions of a firm at a state and then calculating the equilibrium cutoff points by inverting the standard normal distribution. These equilibrium cutoff points correspond to the equilibrium policy rule. ${ }^{18}$ Let $G_{i}\left(d_{i} \mid \omega\right)$ be the cumulative probability that firm $i$ at state $\omega$ decides to scrap $d_{i}$ or fewer SSs. Following the theoretical model,

\footnotetext{
${ }^{18}$ In a study dealing with a similar problem, Olley and Pakes (1996) used nonparametrics to get around the problem of computing a value function needed to obtain a policy function. They described a policy function as a higher-order function of state variables without solving the complex dynamic programming problem to control for an unobserved productivity shock.
} 
this cumulative distribution function can be written as

$$
\begin{aligned}
G_{i}\left(d_{i} \mid \omega\right) & =\int_{-\infty}^{W_{i}\left(d_{i} \mid \omega\right)-W_{i}\left(d_{i}+1 \mid \omega\right)} d F\left(\phi ; \mu v,(k v)^{2}\right) \\
& =\int_{-\infty}^{\bar{W}_{i d_{i}}(\omega)} d \Phi(\nu) \\
& =\Phi\left(\bar{W}_{i d_{i}}(\omega)\right)
\end{aligned}
$$

where $\bar{W}_{i d_{i}}(\omega)=\frac{W_{i}\left(d_{i} \mid \omega\right)-W_{i}\left(d_{i}+1 \mid \omega\right)-\mu v}{k v}$, which represents the normalized cutoff point at which firm $i$ at state $\omega$ is indifferent between divesting $d_{i}$ SSs and scrapping one unit more than $d_{i}$, and $\Phi$ denotes the normal cumulative distribution function. Inverting the above equation, the cutoff point can be expressed as a function of the probability $G_{i}\left(d_{i} \mid \omega\right)$ :

$$
\bar{W}_{d_{i}}(\omega)=\Phi^{-1}\left(G_{i}\left(d_{i} \mid \omega\right)\right)
$$

This normalized cutoff point can be interpreted as the equilibrium policy rule itself. For instance, when firm $i$ knows that the (normalized) sell-off value of its SSs is below $\bar{W}_{i 0}(\omega)$, it does not scrap any SSs. Alternatively, when firm $i$ knows that the (normalized) sell-off value of its SSs falls between $\bar{W}_{i 0}(\omega)$ and $\bar{W}_{i 1}(\omega)$, it sells one SS. If the cutoff points of all possible actions of firm $i$ at state $\omega$ are estimated, then how firm $i$ will behave at the state can be easily predicted.

To estimate the equilibrium policy functions, this estimation approach needs only the estimates of the cumulative probabilities of firm $i$ 's actions at state $\omega, \mathbf{G}_{i}(\omega)=$ $\left(G_{i}(0 \mid \omega), \ldots, G_{i}(\bar{a} \mid \omega)\right)$. While an optimal estimator for $G_{i}\left(d_{i} \mid \omega\right)$ would be a simple nonparametric description of what firm $i$ does at state $\omega$, the choice probabilities are estimated parametrically using the count data regression model of Hausman, Hall and Griliches (1984). This parametric approach is chosen over a nonparametric spell frequency estimator because of the sample size used in this study. With the estimated 
probabilities of all possible actions of firm $i$ at state $\omega, \mathbf{G}_{i}(\omega ; \hat{\gamma})$, the normalized cutoff points can be calculated, and the divestment behavior of firm $i$ at state $\omega$ based on these estimated cutoff points is determined by a randomly drawn sell-off value.

In estimating the policy functions, it is important to control for unobserved state variables. Owing to the presence of unobserved state variables, different equilibria can arise in different outcomes even if these two markets are observationally equal. When using a sample that includes several markets, controlling for the unobserved marketspecific effects is essential for obtaining consistent estimates of the policy functions. Thus, market-specific effects controlling for the effect of these unobservables on the observed equilibrium behavior are included, with the assumption that the unobserved state variables are constant over time.

Transition Probabilities of the Two Exogenous States To estimate the transition probabilities of construction investment $z$ and regional GDP $v$, these two continuous variables are first discretized. ${ }^{19}$ With regard to the transition probabilities of regional GDP $v$, these probabilities are estimated using a multinomial logit model. The maximum (minimum) value of regional GDP $v$ is set to the actual maximum (minimum) value of GDP in each region. On the other hand, it is difficult to estimate the transition probabilities of construction investment because Japan's total amount of construction investment is used as the proxy variable for the demand shifters and consequently, there are only nine data points to estimate the transition probabilities of construction investment. Because of this data limitation, instead of estimating the transition probabilities, it is assumed that the amount of construction investment moves to a lower state from the current state with a probability of 0.9 and that it stays at its 2006 level forever. In other words, it is asumed that the total amount of construction investment in 2006 is the terminal state of $z$.

\footnotetext{
${ }^{19}$ The number of discrete grids for construction investment is 8 . On the other hand, the numbers of discrete grids for regional GDPs are 3 for Hokkaido, 3 for Tohoku, 6 for Tokai, 6 for Kinki, 3 for Chugoku and 1 for Shikoku.
} 
Value Functions As the equilibrium value functions can be used to estimate the dynamic structural parameters in the next step, they are the most important ingredients in this estimation approach. The expected value function of a state is estimated by averaging many simulated paths, starting from the state with the estimated policy functions. This technique, known as forward simulation, was originally utilized by Hotz, Miller, Smith and Sanders (1994) and was extended to multiple agents' decision problems by BBL (2007).

Given a starting state, each simulation path is generated using the following steps:

1. Set a starting state $\omega_{0}=\omega$.

2. Draw normalized sell-off values $\phi_{i 0}$ and $\phi_{-i 0}$ from the standard normal distribution and determine actions $d_{i 0}$ and $d_{-i 0}$.

3. Calculate the per-period cash flow $\pi_{i}\left(\omega_{0}\right)$.

4. Update the current state, $\left(s_{i 0}, s_{-i 0}, z_{0}, v_{0}\right)$, following the divestment decisions and the transition probabilities of these two exogenous variables to a new state, $\left(s_{i 1}, s_{-i 1}, z_{1}, v_{1}\right)$.

5. Repeat steps $1-4$ for $\mathrm{T}$ periods.

The equilibrium value functions are estimated by averaging 200 simulated paths constructed in the above manner. ${ }^{20}$ Each path has a length of 100 periods, and the discount factor $\beta$ is set at 0.925 . Instead of (pseudo) random draws, draws from the Halton sequence are used to reduce the computational burden while keeping the value function approximations precise. According to Train (2003), because they have superior coverage properties and smaller simulation errors, Halton draws are far more effective as

\footnotetext{
${ }^{20}$ The maximum number of SSs scrapped in a period is restricted to four, which is the observed maximum number of SSs scrapped in one period. Even if firms were allowed to divest more than four SSs, the estimated cumulative probability $G_{i}\left(d_{i} \mid \omega ; \hat{\gamma}\right)$ approaches one until $d_{i}=4$ in almost all states. Therefore, this restriction will be innocuous.
} 
a simulation estimator than (pseudo) random draws. The expected value function of firm $i$ starting from $\omega$ can be approximated by

$$
\frac{1}{H} \sum_{h=1}^{H}\left[\sum_{t=0}^{\infty} \beta^{t} \hat{\pi}_{i}^{h}\left(\omega_{t}, \hat{\mathbf{d}}\left(\omega_{t}, \phi_{t}\right), \phi_{i t} ; \theta\right) \mid \omega_{0}=\omega ; \theta\right] .
$$

$H$ is the number of draws from the Halton sequence. ${ }^{21}$

\subsection{Second-step Estimation}

In the second step, the dynamic structural parameters, which are the mean and variance of the sell-off value distribution, and the fixed costs are estimated. In this estimation, the parameter values of the sell-off value distribution and fixed costs are set to satisfy equilibrium condition (16) at each state $\omega$.

Let $x \in X$ index the equilibrium conditions, so that each $x$ denotes a particular $\left(i, \omega, d_{i}^{\prime}\right)$ combination, and $\theta$ be the parameters estimated in this step. The difference between the equilibrium value function for firm $i$ at $\omega$ and an alternative value function

${ }^{21}$ To reduce the computational burden, the linearity assumption in the payoff function is exploited. Recall that the per-period cash flow of firm $i$ at state $\omega$ is

$$
\begin{aligned}
\hat{\pi}_{i}\left(\omega_{t} ; \theta\right) & =\hat{u}_{i t}+\phi_{i t} \hat{d}_{i t} \\
& =\tilde{u}_{i t}-f_{s s} s_{i t}+\left(\mu v_{t}+\left(k v_{t}\right) \nu_{i t}\right) \hat{d}_{i t} .
\end{aligned}
$$

$\tilde{u}_{i t}$ is the estimate of the product market profit of firm $i$ at state $\omega_{t}$ but does not include the fixed costs $f_{s s} s_{i t}$, and $\hat{d}_{i t}$ is the estimated divestment action, which depends on the estimates of the choice probabilities, $\mathbf{G}\left(\omega_{t} ; \hat{\gamma}\right)$. Note that the unknown parameters $(\mu, k)$ and $f_{s s}$ enter linearly in the perperiod cash flow. Therefore, the expected value function of firm $i$ starting from $\omega$ can be rewritten as

$$
\begin{aligned}
\hat{V}_{i}(\omega ; \theta) & =\frac{1}{H} \sum_{h=1}^{H}\left[\sum_{t=0}^{\infty} \beta^{t} \tilde{u}_{i t}^{h}-f_{s s} \sum_{t=0}^{\infty} \beta^{t} \hat{s}_{i t}^{h}+\mu \sum_{t=0}^{\infty} \beta^{t} \hat{d}_{i t}^{h} v_{t}^{h}+k \sum_{t=0}^{\infty} \hat{d}_{i t}^{h} v_{t}^{h} \nu_{i t}^{h}\right] \\
& =\frac{1}{H} \sum_{h=1}^{H} \sum_{t=0}^{\infty} \beta^{t} \tilde{u}_{i t}^{h}-f_{s s} \frac{1}{H} \sum_{h=1}^{H} \sum_{t=0}^{\infty} \beta^{t} \hat{s}_{i t}^{h}+\mu \frac{1}{H} \sum_{h=1}^{H} \sum_{t=0}^{\infty} \beta^{t} \hat{d}_{i t}^{h} v_{t}^{h}+k \frac{1}{H} \sum_{h=1}^{H} \sum_{t=0}^{\infty} \hat{d}_{i t}^{h} v_{t}^{h} \nu_{i t}^{h} .
\end{aligned}
$$

By this linearity, the computation of each value function is done only once when searching for the estimates of the parameters $\left(\mu, k, f_{s s}\right)$ in the second step. 
at this state is defined as follows:

$$
g(x ; \theta, \hat{\alpha}, \hat{\gamma})=\hat{V}_{i}\left(\omega ; \mathbf{d}^{*}(\omega, \phi) ; \theta, \hat{\alpha}, \hat{\gamma}\right)-\hat{V}_{i}\left(\omega ; d_{i}^{\prime}\left(\omega, \phi_{i}\right), \mathbf{d}_{-i}^{*}\left(\omega, \phi_{-i}\right), ; \theta, \hat{\alpha}, \hat{\gamma}\right)
$$

where $d_{i}^{\prime}\left(\omega, \phi_{i}\right)$ is an alternative nonequilibrium policy function. These estimated value functions depend on the first-stage estimates, the choice probabilities $G\left(d_{i} \mid \omega ; \hat{\gamma}\right)$, and the profit function parameters $\hat{\alpha}$, as well as the parameters of interest in the second step, $\theta=(\mu, k)$. The equilibrium condition is satisfied at $\theta$ if $g(x ; \theta, \hat{\alpha}, \hat{\gamma}) \geq 0$. The goal of the second-step estimation is to find the values of the parameters that best satisfy the entire set of inequalities. However, it is difficult to do this because the entire state space is quite large and there are many alternative policies. Therefore, following BBL (2007), a small subset of the inequalities to impose in the estimation is chosen. Specifically, 500 equilibrium conditions are chosen randomly and, to obtain alternative value functions, the estimated policy functions are perturbed by adding a random term. ${ }^{22}$

The objective function is defined as follows:

$$
Q(\theta, \hat{\alpha}, \hat{\gamma})=\frac{1}{N_{I}} \sum_{j=1}^{N_{I}}\left(\min \left\{g\left(x_{j} ; \theta, \hat{\alpha}, \hat{\gamma}\right), 0\right\}\right)^{2}
$$

where $N_{I}$ is the number of randomly chosen inequalities. The estimator of the structural parameters is a solution $\hat{\theta}$ to the problem

$$
\min _{\theta} Q(\theta, \hat{\alpha}, \hat{\gamma})
$$

This is a two-step estimator as discussed in Newey and McFadden (1994) and, thus,

\footnotetext{
${ }^{22}$ That is, a random term $\xi$ is drawn from the normal distribution with a mean of zero and a standard deviation of 0.3 and added to the estimated equilibrium choice probabilities. Accordingly, the alternative cumulative choice probabilities of all possible actions of firm $i$ at state $\omega, \mathbf{G}_{i}(\omega)$, become $\hat{\mathbf{G}}_{i}(\omega)+\xi_{i}$. Using the alternative probabilities, the alternative cutoff points for divestments as explained in (21) in the previous section are calculated.
} 
the variance-covariance matrix of $\hat{\theta}$ is complicated since it depends on the variances of the first-step parameter estimates $\hat{\alpha}$ and $\hat{\gamma}$. Furthermore, as the equilibrium and alternative value functions are approximated by a simulation method, simulation error also affects the variance of the structural parameter estimates $\hat{\theta}$ as discussed in McFadden (1989) and Pakes and Pollard (1989). Accounting for these influences, the estimate of the variance and covariance matrix $\Omega$ is given by

$$
\left(1+\frac{1}{H}\right) \mathbf{Q}_{\theta \theta}^{-1} \mathbf{Q}_{\theta(\alpha, \gamma)} \boldsymbol{\Sigma}_{\alpha \gamma} \mathbf{Q}_{\theta(\alpha, \gamma)}^{\prime} \mathbf{Q}_{\theta \theta}^{-1}
$$

where $H$ is the number of simulation draws from the Halton sequence, $\mathbf{Q}_{\theta \theta} \equiv \frac{\partial^{2}}{\partial \theta \partial \theta} Q(\theta, \hat{\alpha}, \hat{\gamma})$, $\mathbf{Q}_{\theta(\alpha, \gamma)} \equiv \frac{\partial^{2}}{\partial(\alpha, \gamma) \partial \theta} Q(\theta, \hat{\alpha}, \hat{\gamma})$, and $\boldsymbol{\Sigma}_{\alpha \gamma}$ represents the variance of the estimates of the parameters in the first step.

\section{Estimation Results}

Having described the model of distribution facility divestment in dynamic oligopoly and the estimation procedure using the two-step approach of BBL (2007), the stage is now set to present the results of the estimation.

\subsection{Results of the First-step Estimation}

Demand Function Table 5 shows the results of the demand function estimation. In estimating the demand function, one-period lagged values of price and quantity serve as instrumental variables. To control for market-specific effects on quantity, dummy variables for regional markets are also included. The estimated price coefficient $\alpha_{1}$ has the expected sign, and its value of 1.3 falls within a reasonable range. All of the region-specific effects are significant, and demand conditions are different across the six regions. To account for changes in demand, the amount of construction investment in Japan as a whole is used as the demand shifter in all regional markets. Thus, while the 
nationwide trend in cement demand is accounted for by the demand shifter, the demand level in an individual market is represented by the fixed effect. The reason is that although regional data on construction investment is available, it is almost perfectly correlated with the regional quantity supplied, meaning that it was not possible to find reasonable estimates of price elasticity.

Cost Function The parameter estimates of the cost function are presented in Table 6. As expected, the more SSs a firm has within a region, the lower is its marginal cost of delivering products, likely because the larger number of SSs allows it to avoid long-haul secondary distribution. The adjusted R-square of the estimated cost function is around 0.78 , which indicates that the fit of this specification is reasonably good.

Furthermore, to check how the model can predict the observed outcomes, the Cournot equilibrium in each region for each year is computed using the estimated demand and cost functions, and the model predictions are then compared with the observed quantities. The result is presented in Table 7, which indicates that the model can predict the observed quantities quite well in the upper quantiles, although in the lower quantiles, the predictions are relatively imprecise. The prediction error in the lower quantile, however, does not pose much of a problem for the analysis here since the output share of small firms is miniscule and the effect on the total quantities is limited.

Further, this result indicates that the payoff-relevant state variable $s_{\text {irt }}$ describes the behavior of firm $i$ in region $r$ well. As mentioned, it is assumed that regional markets are independent of each other. However, it is of course possible that firm $i$ 's SSs in markets adjacent to market $r$ are used for cement supply in market $r$ and the SSs can be payoff-relevant state variables in the market. ${ }^{23}$ In practice, though, the

\footnotetext{
${ }^{23}$ Of the regions included in this study, the Kinki region is adjacent to the Tokai and Chugoku regions, while the Tohoku region is adjacent to the Kanto and Hokuriku regions, which are not included in my sample. On the other hand, the Hokkaido and Shikoku regions are completely isolated markets because these two regions are separate islands.
} 
model developed with the independent market assumption explains the actual supply behavior in the regional markets well.

Policy Functions To obtain the equilibrium policy rule, first, the probabilities of observing all possible actions at each state are estimated using a count data model, and the cumulative probabilities are calculated. Then, the set of cutoff points of firm $i$ at state $\omega, \overline{\mathbf{W}}_{i d_{i}}(\omega)$, is calculated by inverting the (standard) normal distribution and evaluating the inverted distribution at $\mathbf{G}_{i}(\omega ; \hat{\gamma})$ in the way proposed in the previous section.

Table 8 presents the result of the Poisson regression. ${ }^{24}$ In this estimation, firms' actions are explained by the state variables, firms' own number of SSs, competitors' number of SSs, the exogenous demand shifter, and regional economic condition. In addition, market fixed effects are considered in order to control for the possible existence of an unobserved state variable that affects the equilibrium behavior.

To check the precision of the estimated policy rule, actions predicted by the estimated policy rule are compared with the observed actions. At all observed states, the sell-off values of firms' SSs are chosen randomly from the standard normal distribution and the action of each firm then is determined based on the estimated cutoff points, which are derived from the estimated probabilities of actions and the sell-off value of the firm's SSs. This procedure is repeated 100 times and the percentages of actions are calculated. For the comparison, the same exercise is conducted by using a logistic and uniform distribution instead of the standard normal distribution. Table 9 shows the results of this exercise and indicates that the normal distribution can predict divestment behaviors better than the extreme value distribution. The correlation coefficient also supports the normal distribution.

\footnotetext{
${ }^{24} \mathrm{An}$ ordered probit model for divestment actions is also estimated, but the result is not substantially different from that of the Poisson regression.
} 


\subsection{Result of the Second-step Estimation}

The second step of the estimation consists of searching for the values of the parameters $\left(\mu, k, f_{s s}\right)$ that best satisfy the equilibrium conditions, which are defined as the distance between the equilibrium value function and a randomly chosen alternative value function. Parameter estimates of the sell-off value distribution and fixed cost are presented in Table 10. The estimated fixed costs are about 110 million yen, an amount that is not negligible for cement firms, given that it presents about $13 \%$ of their total supply costs and thus has a substantial impact on profits. The estimated sell-off value distribution is very tight. This result implies that cement firms knows the sell-off values of competitors' SSs with considerable certainty. Equivalently, it means that they face very little uncertainty about their rivals' divestment behavior. A likely explanation of this result is that land prices are a very good proxy for sell-off values and that firms can estimate the sell-off value that rivals can realize by removing SSs from such easily accessible information.

To examine whether the estimates of the sell-off value distribution are reasonable or not, they are compared with the land values in the regions studied here. As previously noted, the land value of an SS accounts for the largest part of its sell-off value. Table 11 presents the estimated means and variances of the sell-off value distributions evaluated at the means of regional GDPs and 50\% intervals of land values of SSs using information on land prices and SSs' land area. The land value in a region is calculated by multiplying land prices by the mean SS land area. ${ }^{25}$ Although the figures of land prices used here admittedly are somewhat rough and are not actual SS land prices themselves, the estimated sell-off value distributions are nevertheless likely to reflect

\footnotetext{
${ }^{25}$ The land prices used for this purpose are land prices in industrial areas and are collected from public notifications of land prices 1998-2006, which are piblished annually in March by the Ministry of Land, Infrastructure, Transport and Tourism. The mean SS land area in an individual region is calculated from the Annual Securities Reports of Taiheiyo Cement Corp. Unfortunately, other cement firms do not publish information on their SSs. Therefore, the mean SS area in Table 11 is calculated using only the SS area of Taiheiyo Cement Corp.
} 
the sell-off value of SSs.

\section{Simulation Exercise}

Having estimated the structural parameters governing the dynamics of the Japanese cement industry, the stage is now set to conduct a simulation exercise in order to examine the main issue of interest of this study, namely the welfare impact of the mergers seen in the Japanese cement industry.

This experimental exercise considers two scenarios - the actual course of events and a counterfactual in which no mergers take place - and then compares the market outcomes. Although the counterfactual market should have the same number of firms as seen in the real world before the mergers, the computational burden involved in solving for an MPE would be severe, meaning that conducting a complete experiment is difficult. For example, in 1993 (just before the four big mergers), the average number of firms operating in a market was about nine (Table 2). To solve the dynamic game with this many firms is not prohibitive but extremely computationally burdensome. Because of this computational constraint, two markets are considered here that are smaller than the actual market. The first, which approximates the actual market structure, is a market with four firms, of which three are merged firms and one is not; the second market, which is the counterfactual without mergers, is one with seven independent firms.

A very useful algorithm for computing equilibria of stochastic dynamic games is the one developed by Pakes and McGuire (1994), which has become a widely used tool for applied research in the field. ${ }^{26}$ Although their algorithm could be applied here, to alleviate the computational burden an alternative way of computing an MPE using

\footnotetext{
${ }^{26}$ Pakes and McGuire (2001) proposed a stochastic algorithm to break the 'curse of dimensionality' in solving for the equilibria of a recurrent class model. Although their algorithm can deal with a large number of firms, the model considered in this study does not belong to this class.
} 
the unique structure of the model considered here is employed. ${ }^{27}$ In this model, the movements of the endogenous state variables are weakly unidirectional. The number of a firm's SSs only goes down, and once these state variables reach the terminal state, this state lasts forever. Calculating the value functions in the terminal state is straightforward, because they are just the sum of future cash flows at the state, and the remaining states can then be solved by a backward induction procedure. ${ }^{28}$

Once the model is solved for both market structures, it is possible to obtain simulation paths and compare the two outcomes in order to evaluate the effect of the mergers on total welfare. The starting state in the counterfactual market without any mergers is based on the average size of the largest seven firms in the observed six markets in 1993, the year just before the merger wave. The state vector starts at $\omega=(11,10,9,8,7,4,4, z, v)$. The other market with three merged firms starts at $\omega=(21,15,9,8, z, v)$. This starting state is based on the fact that if all observed mergers had occurred in 1994, the average shares across regions in terms of the number of SSs for the merged firms would have been $40 \%, 25 \%$ and $15 \%{ }^{29}$ The actual construction investment in 1994 is used as the starting demand level $z$ for both markets, and the mean of regional GDPs is used as $v .^{30}$

The results are summarized in Table 12. 100 sample paths having a length of 10 years for each market are generated, and the sample average of these paths is reported.

\footnotetext{
${ }^{27}$ In this simulation exercise, two sample equilibria are computed by this algorithm. Since this model does not satisfy a sufficient condition for uniqueness of equilibria, there is the possibility that multiple equilibria arise. Movements through the state space are unidirectional while the reaction functions may not necessarily intersect only once. Therefore the presence of multiple equilibria cannot be ruled out. A possible remedy is to start the algorithm from various starting values, and that is what is done here.

${ }^{28}$ This solution algorithm is very similar to that provided by Judd, Schmedders and Yeltekin (2006). They consider a patent race where the state variables only go up to the higher states.

${ }^{29}$ Four mergers took place but the same firm was involved in two of them: Onoda Cement Crop. merged with Chichibu Cement Corp. in 1994, foming Chichibu-Onoda Cement Corp. Chichibu-Onoda Cement Corp. then merged with Nihon Cement Corp. in 1998 to become Taiheito Cement Corp., the largest cement firm in Japan.

${ }^{30}$ Regional GDP $v$ could be time varying. However, allowing regional GDP $v$ to move adds an additional computational burden. Thus, this state variable is fixed over time.
} 
CONSUMER SURPLUS is based on equation (6). PRODUCER SURPLUS is based on equation (5) but does not include fixed costs. FIXED COSTS indicates the sum of the fixed costs incurred, while SELL-OFF VALUE is the total sell-off values of SSs scrapped. TOTAL WELFARE measures the sum of the consumer surplus, the producer surplus, the fixed costs, and the sell-off values. The last column in the table shows the welfare effects of the mergers. The consumer surplus decreased by 25.47 billion yen, while the producer surplus increased by 32.10 billion yen. Furthermore, the scrapping of SSs saves fixed costs of 6.77 billion yen and generates 16.10 billion yen from the sell-off. Thus, the total welfare effect of the mergers is 29.5 billion yen. It should be noted, though, that relative to the size of the industry, these figures are very small. The mergers improved the total welfare by less than $2 \%$ in this experiment.

The result thus suggests that the mergers increased total welfare, but a large part of the positive welfare effect stems from the increase in the producer surplus. An increase in the number of SSs that a firm has as a result of a merger allows the firm to allocate supply to service stations close to its customers, thus avoiding costly long-haul delivery, providing merged firms with a cost efficiency gain. This efficiency gain is large enough to outweigh the loss of the consumer surplus. This effect is considered as the traditional synergy effect of a merger. The third and fourth rows in Table 12 show that in the market with mergers, as a result of more SSs being scrapped, firms realized greater fixed cost savings and generated more income from sell-offs than in the counterfactual market with no mergers. These two effects improved producer welfare. Surprisingly, the total amount of these two values exceeds the traditional welfare effect. ${ }^{31}$ This result emphasizes the importance of taking into account the effects of outcomes arising from the dynamic decision process on the total welfare in evaluating mergers, which has been pointed out by Stigler (1968) and by Berry and Pakes (1993).

\footnotetext{
${ }^{31}$ This estimate is the upper bound of the total welfare effect of the mergers because the sell-off values themselves are net gains to firms in the industry but not net gains to society. However, even if the sell-off values are excluded from the total welfare calculation, the fixed costs savings account for a substantial part of the total welfare gain.
} 
A remaining question is why merged firms scrap more SSs that firms not involved in mergers. Scrapping an SS can be regarded as a public good that must be provided privately. The reason is that the increase in price from the reduction in SSs benefits all firms and they have an incentive for free-riding on someone else's divestment. Merged firms can partly internalize this spillover effect of divestment and are therefore more likely to divest. Consider the case where a firm, A, merges with one of its competitors, B. Suppose that after the merger, the merging firm scraps one of its SSs and the equilibrium price rises as a result. In this case, the benefit of the higher price enjoyed by firm B (A) is completely realized in terms of firm A (B)'s own profit. The merged firm can partly internalize the business-stealing effect and, consequently, has a stronger incentive for divestment than does a nonmerged firm. ${ }^{32}$

In oligopolies, there is a tendency for capital stock to be greater than the industry as a whole would want. In the case of the cement industry, this means that there is a tendency for the total number of SSs to be excessive. In such situation of capital, reducing the number of SSs can be beneficial at least for firms in the industry and possibly from a total welfare perspective. The simulation results presented in Table 12 show that the mergers promoted divestment through the internalization effect explained above and increased producers' profits through fixed costs savings, and improved total welfare since the positive effect for firms is larger than the negative effect for consumers.

An important point is that the welfare loss occurring as a result of the excessive capital stock is more likely to be severe in periods of industry decline because welfare is expected to be increasingly impaired as the socially desired amount of capital decreases (on this point, see example 1 in Mankiw and Whinston 1986). This implies that because the socially desirable level of capital decreases with the decline in demand, welfare is increasingly impaired by the existence of excess capital in declining industries.

\footnotetext{
${ }^{32}$ Note that in general, a merger raises the equilibrium price and profits. Therefore, higher profits have the opposite effect on the incentive for divestment. The simulation result indicates that the internalization effect outweighs this profit effect and mergers consequently promote the scrapping of distribution facilities.
} 
Therefore, resolving the problem of excess capital can be more beneficial in declining industries and can be a specific reason for justifying mergers in such industries.

\section{Conclusion}

In oligopolistic industries, the presence of a business-stealing effect and fixed costs creates a wedge between the capital stock that is optimal for individual firms and the capital stock optimal for the industry as a whole. In the case of declining industries, the amount of capital divestment is likely to be less than what would maximize the industry's total profit. Although removing excess capital stock would lead to an increase in total industry profit, such divestment is not undertaken voluntarily because once a firm removes its capital stock, part of its business will be captured by its rivals. Thus, regardless of the decline in demand in such an industry, the situation of excess capital will persist.

Mergers are expected to solve this situation. Merged firms can internalize the business-stealing effect and promote the reduction in capital stock. However, merged firms usually do not consider maximizing the total welfare when deciding whether scrap capital or not and mergers in declining industries consequently are not necessarily beneficial for society as a whole.

Against this background, this study focused on the role of mergers as a means to promote divestment and examined whether merger-induced divestments could increase not only producer profits but also total welfare. To analyze mergers in an environment where the industry's amount of capital constantly changes and the demand level shifts down over time, the study used the Markov-perfect equilibrium framework of Ericson and Pakes (1995) to describe the dynamic divestment decision process. The simulation exercise showed that merged firms had more incentive to scrap their facilities and that such divestments as a result of mergers could lead to the improvement of welfare. In particular, savings on fixed costs (as well as the realization of the sell-off value of 
divested assets) made very large contributions to the improvement in welfare.

In addition to the academic interest, this study also has an important policy implication. US horizontal merger guidelines states that "the agencies consider mergerspecific, cognizable reductions in fixed costs, even if they cannot be expected to result in direct short-term, procompetitive price effects because consumers may benefit from them over the longer term even if not immediately". ${ }^{33}$ The results of this study showed that horizontal mergers facilitated divestment and thereby reduced fixed costs. They also showed that this fixed cost savings was a substantial contribution to total surplus. According to the US guidelines, such mergers will not be accepted because, even in long run, price reduction is not expected to take place. However, if the total surplus is to be the welfare criterion, the mergers possibly had better be accepted. This study, therefore, will provide a critical policy question to the competition policy authority.

Finally, possible extensions as well as some shortcomings of this study should be noted. While the analysis here focused on the after-merger behavior, a more realistic approach would incorporate endogenous merger decision processes into the empirical model to investigate the merger incentive itself. Studies by Gowrisankaran (1999) and Pesendorfer (2005) provide the theoretical framework that could make this possible. Furthermore, this study analyzed only the unilateral effect of horizontal mergers. The reduction in the number of incumbents may increase the possibility of collusive conduct within a market. In almost all cases, collusion raises prices and thus is detrimental to consumers, lowering the consumer surplus further. Therefore, such collusive conduct has important welfare implications and the results obtained in this study might be overturned. Modeling collusion in a dynamic world is one of the open research questions in the field of industrial organization. A final point is that the present study treated each region as an independent market and assumed that cement firms decided their divestment strategies without consideration of the effect of divestment on other markets,

\footnotetext{
${ }^{33}$ US department of Justice and Federal Trade Commission, "Commentary on the Horizontal Merger Guidelines,", March 2006, p.58.
} 
even if cement firms operated across several regions. If markets exists are interrelated each other, the divestment decision problem will be more complicated than the simplified description in this study. Jia (2008) relaxes this assumption of independence in a static oligopoly setting. Although it is challenging, developing a model allowing interdependence across markets in a dynamic game would help to further improve the present study by making it more closely reflect reality.

\section{References}

[1] Ackerberg, D., Benkard, C.L., Berry, S., and A. Pakes (2006) "Econometric Tools for Analyzing Market Outcomes," Working Paper prepared for Heckamn, J.J., and E. Leamer (eds.), Handbook of Econometrics, Volume 6.

[2] Aguirregabiria, V., and P. Mira (2007) "Sequential Estimation of Dynamic Discrete Games," Econometrica, 75, 1-54.

[3] Bajari, P., Benkard, C.L., and J. Levin (2007) "Estimating Dynamic Models of Imperfect Competition," Econometrica, 75(5), 1331-1370.

[4] Berry, S., and A. Pakes (1993) "Some Applications and Limitations Of Recent Advances in Empirical Industrial Organization," American Economic Review, 83, $247-252$.

[5] Berry, S., and E. Tamer (2006) "Identification in Models of Oligopoly Entry," in Blundell, R., Newey, W., and T. Persson (eds), Advances in Economics and Econometrics, Volume 2, Cambridge University Press, Cambridge.

[6] Berry, S., Levinsohn, J., and A. Pakes (1995) "Automobile Price in Market Equilibrium," Econometrica, 63, 841-890.

[7] Besanko, D., Draszelski, U., Lu, L., and M. Satterthwaite (2008) "Lumpy Capacity Investment and Disinvestment Dynamics," Mimeo, Harvard University. 
[8] Choeng, K., and K. Judd (2006) "Mergers and Dynamic Oligopoly," Journal of Economic Dynamics and Control, forthcoming.

[9] Collard-Wexler, A (2006) "Demand Fluctuations and Plant Turnover in ReadyMix Concrete," Mimeo, NewYork University.

[10] Doraszelski, U., and A. Pakes (2006) "A Framework for Applied Dynamic Analysis in IO," in Armstrong, M., and R. Porter (eds), Handbook of Industrial Organization, Volume 3, North-Holland, Amsterdam.

[11] Doraszelski, U., and M. Satterthwaite (2007) "Computable Markov Perfect Industry Dynamics: Existence, Purification and Multiplicity," Mimeo, Harvard University.

[12] Ericson, R., and A. Pakes (1995) "Markov Perfect Industry Dynamics: A Framework for Empirical Work," Review of Economic Studies, 62, 53-82.

[13] Fudenberg, D., and J. Tirole (1986) "A Theory of Exit in Duopoly," Econometrica, $54,943-960$.

[14] Ghemawat, P., and B. Nalebuff (1985) "Exit," Rand Journal of Economics, 16, $184-192$.

[15] Ghemawat, P., and B. Nalebuff (1990) "The Devolution of Declining Industries," Quarterly Journal of Economics, 105 165-186

[16] Gowrisankaran, G (1999) "A Dynamic Model of Endogenous Horizontal Mergers," Rand Journal of Economics, 30, 56-83.

[17] Hausman, J., Hall, B.H., and Z. Griliches (1984) "Econometric Models For Count Data With Application to the Patents-R\&D Relationship," Econometrica, 52, 909-938. 
[18] Hotz, V.J., Miller, R.A., Sanders, S., and J. Smith (1994) "A Simulation Estimator for Dynamic Models of Discrete Choice," Review of Economic Studies, 61, 265289.

[19] Jia, P. (2008) "What Happens When Wal-Mart Comes to Town: An Empirical Analysis of the Discount Retail Industry," Econometrica, 76, 1263-1316.

[20] Judd, K., Schmedders, K., and S. Yeltekin (2002) "Optimal Rules for Patent Races," Working Paper, Hoover Institution.

[21] Mankiw, G., and M. Winston (1986) "Free Entry and Social Inefficiency," Rand Journal of Economics, 17, 49-58.

[22] Maskin, E., and J. Tirole (2001) "Markov Perfect Equilibrium: Observable Actions," Journal of Economic theory, 100, 191-219.

[23] McFadden, D. (1989) "A Method of Simulated Moments for Estimation of Discrete Response Models without Numerical Integration," Econometrica, 57, 995-1027.

[24] Myojo, S., and H. Ohashi (2008)"Evaluating Merger Remedies in a Dynamic Environment: Revisiting the Steel Merger in 1970," Mimeo.

[25] Newey, W.K., and D. McFadden (1994) "Large Sample Estimation and Hypothesis Testing," in R.F. Engle and D. McFadden (eds.), Handbook of Econometrics, Volume 4, North Holland, Amsterdam, 2111-2245.

[26] Nishiwaki, M. (2007) "A Dynamic Analysis of Horizontal Mergers: The Case of the Japanese Cement Industry," Mimeo.

[27] Odagiri, H. (2008) "Mergers and Efficiency: Theory, Empirical Evidence and Competition Policy in Japan," in Gulger, K., and B.B. Yurtiglu (eds), The Economics of Corporate Governance and Mergers, Edward Elgar. 
[28] Olley, S., and A. Pakes (1996) "The Dynamics of Productivity in the Telecommunications Equipment Industry," Econometrica, 64, 1263-1298.

[29] Pakes, A. (1986) "Patents as Options: Some Estimates of the Value of Holding European Patent Stocks," Econometrica, 54, 755-784.

[30] Pakes, A. (1994) "Dynamic Structural Models, Problems and Prospects: Mixed Continuous Discrete Controls and Market Interactions," in Sims, C., and J. Laffont (eds), Advance in Econometrics, Proceedings of the 1990 Meetings of the Econometric Society, Cambridge University Press, Cambridge, U.K..

[31] Pakes, A. (2008) "Theory and Empirical Work on Imperfectly Competitive Markets," Mimeo, Harvard University.

[32] Pakes, A., and P. McGuire (1994) "Computing Markov Perfect Nash Equilibria: Numerical Implications of a Dynamic Differentiated Product Model," Rand Journal of Economics, 25, 555-589.

[33] Pakes, A., and P. McGuire (2001) "Stochastic Approximation for Dynamic Models: Markov Perfect Equilibrium and the 'Curse' of Dimensionality," Econometrica, 69, $1261-1281$.

[34] Pakes, A., and D. Pollard (1989) "Simulation and the Asymptotics of Optimization Estimators," Econometrica, 57, 1027-1058.

[35] Pakes, A, Ostrovsky, M., and S. Berry (2005) "Simple Estimators of the Parameters of Discrete Dynamic Games (with Entry/Exit Examples)," Rand Journal of Economics, forthcoming.

[36] Pesendorfer, M. (2003) "Horizontal Mergers in the Paper Industry," Rand Journal of Economics, 34, 495-513. 
[37] Pesendorfer, M. (2005) "Mergers Under Entry," Rand Journal of Economics, 36, 661-679.

[38] Pesendorfer, M., and P. Shmidt-Dengler (2008) "Asymptotic Least Squares Estimators for Dynamic Games," Review of Economic Studies, 75, 901-928.

[39] Rosen, A. (2007) 'Identification and Estimation of Firms' Marginal Cost Functions with Incomplete Knowledge of Strategic Behavior," Mimeo, University College London.

[40] Rust, J. (1987) "Optimal Replacement of GMC Bus Engines: A Empirical Model of Harold Zurcher," Econometrica, 55, 999-1033.

[41] Rust, J. (1994) "Structural Estimation of Markov Decision Processes," in Engle, R., and D.L. McFadden (eds), Handbook of Econometrics, Volume 4, Elsevier Science, Amsterdam.

[42] Ryan, S. (2006) "The Cost of Environmental Regulations in a Concentrated Industry," Mimeo, MIT, Harvard.

[43] Suzumura, K., and K. Kiyono (1987) "Entry Barriers and Economic Welfare," Review of Economic Studies, 19, 157-167.

[44] Train, K. (2003) Discrete Choice Methods With Simulation, Cambridge University Press, Cambridge.

[45] Whinston, M. (1988) "Exit with Multiplant Firms," Rand Journal of Economics, $19,568-588$. 
Figure 1: Trend in Cement Consumption (tons) and Construction Investment (billion yen)

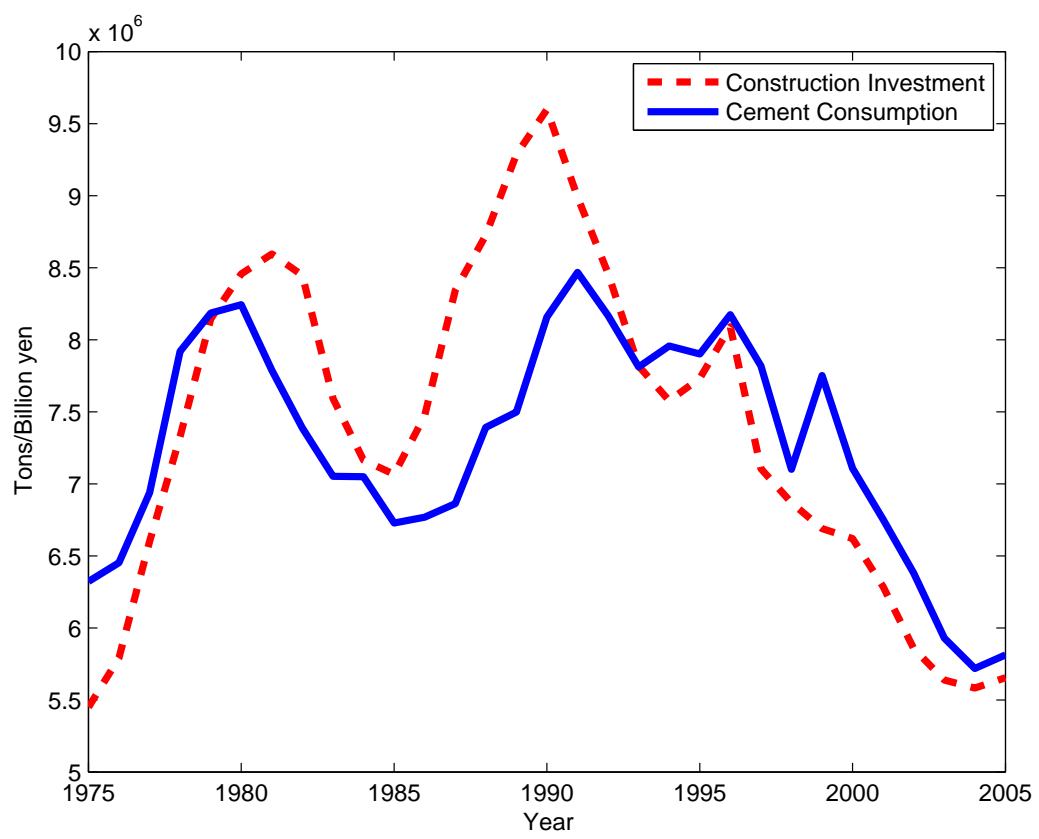

Figure 2: Trend in the Number of Cement Distribution Facilities (Service Stations)

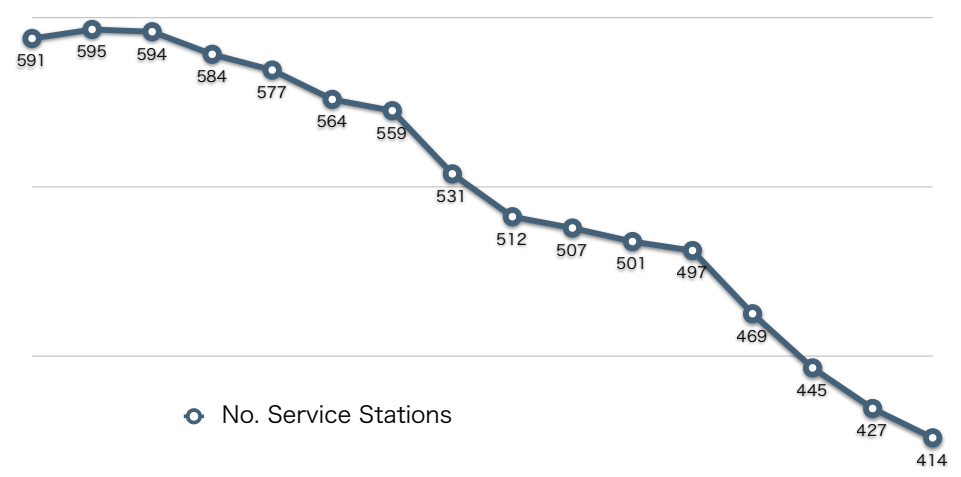

1991199219931994199519961997199819992000200120022003200420052006 
Figure 3: Trend in Price from 1991 to 2006 (yen)

13,000

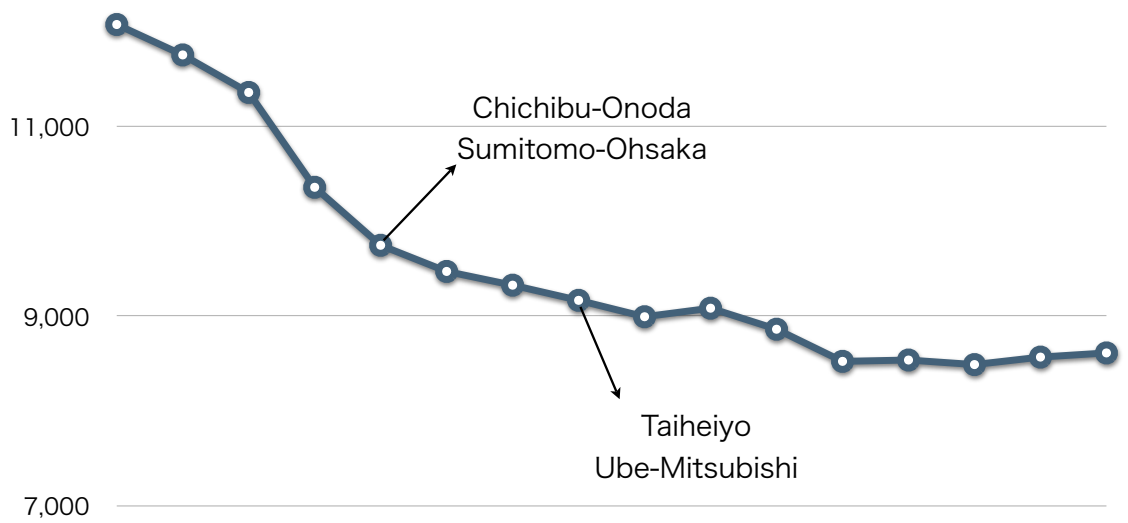

5,000

1991199219931994199519961997199819992000200120022003200420052006

Figure 4: Trend in the Number of Service Stations: Merged Firms and Non-Merged Firms

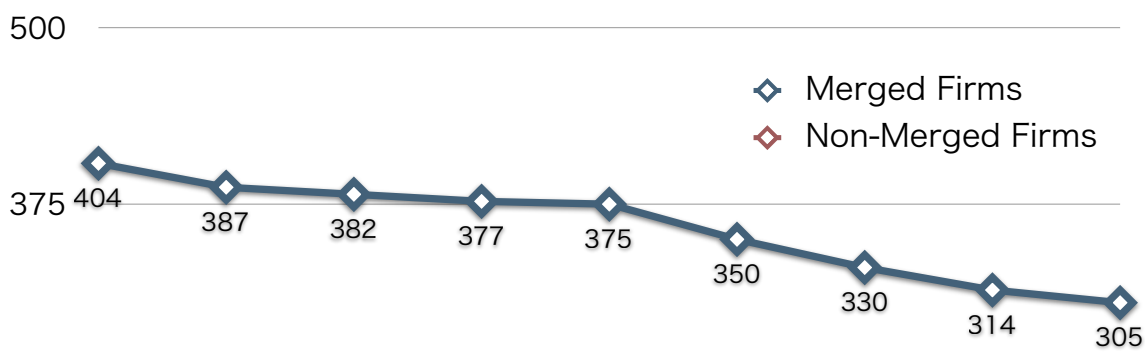

250

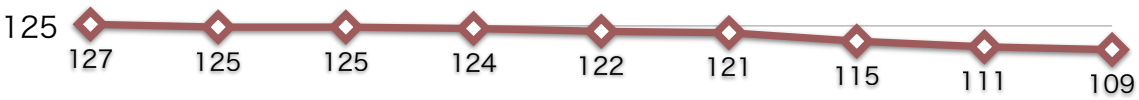

$\begin{array}{lllllllll}1998 & 1999 & 2000 & 2001 & 2002 & 2003 & 2004 & 2005 & 2006\end{array}$




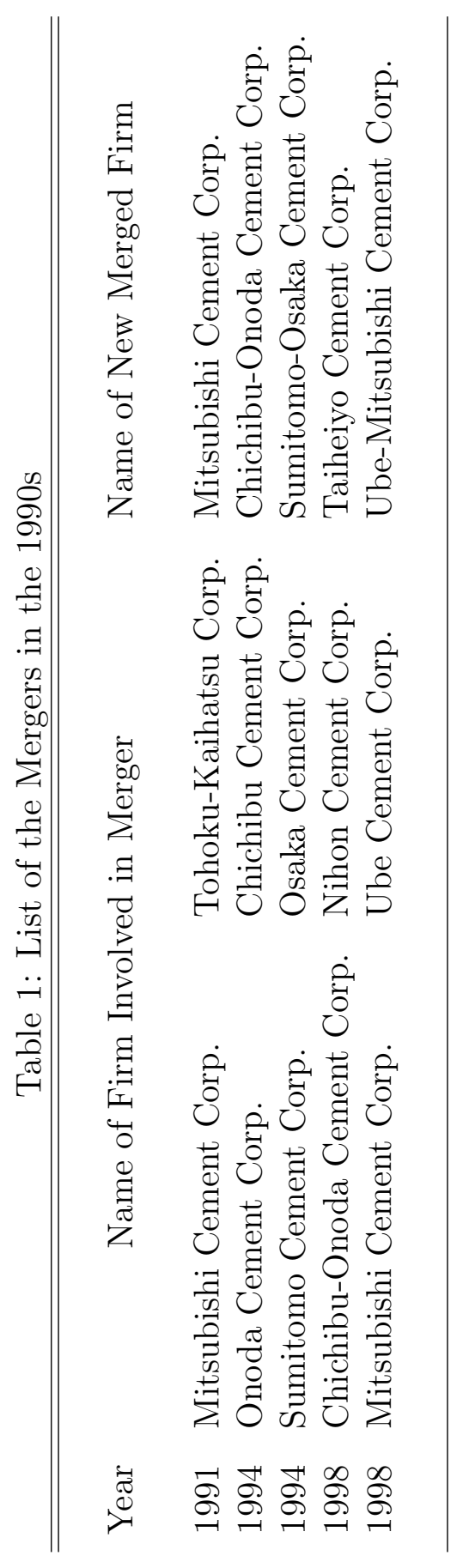


Table 2: Number of Firms per Region Before and After the Mergers of the 1990s

\begin{tabular}{lcccc}
\hline \hline Number of firms & Mean & Std. dev. & Min. & Max. \\
Before mergers (1993) & 9.12 & 1.66 & 7 & 12 \\
& & & & \\
After mergers (1998) & 5.95 & 1.21 & 4 & 8 \\
\hline
\end{tabular}

Table 3: Three-Firm Concentration Ratio

The concentration ratio is measured in terms of the number of service stations in each regional market.

\begin{tabular}{lcccc}
\hline \hline & Mean & Std. dev. & Min. & Max. \\
$\begin{array}{lcccc}\text { Before mergers } \\
1993\end{array}$ & 0.5642 & 0.1185 & 0.4410 & 0.7931 \\
& & & & \\
$\begin{array}{l}\text { After mergers } \\
1994\end{array}$ & 0.6312 & 0.1103 & 0.4950 & 0.7929 \\
1998 & 0.8439 & 0.0918 & 0.7156 & 0.9539 \\
& & & & \\
\hline
\end{tabular}

Table 4: Summary Statistics

\begin{tabular}{lccccc}
\hline \hline Variables & & & & & \\
& Obs. & Mean & Std. dev. & Min. & Max. \\
PRICE & 54 & 8966.025 & 623.317 & 8085.889 & 10258.79 \\
CEMENT CONSUMPTION & 54 & 5469154 & 2359033 & 2416937 & $1.05 E+07$ \\
CONSTRUCTION INV. & 54 & 50793.61 & 23198.08 & 16040.66 & 94054.07 \\
REGIONAL GDP & 54 & 44146.54 & 26756.24 & 13528.8 & 83537.45 \\
SUPPLY QUANTITY & 261 & 1091781.774 & 850884.1383 & 114650 & 3447859 \\
NO.SS & 261 & 9.1341 & 5.5748 & 1 & 26 \\
DIVESTMENT & 261 & 0.3295 & 0.7485 & 0 & 4 \\
& & & & & \\
\hline
\end{tabular}


Table 5: Estimates of Demand Function Parameters

PRICE is the logarithm of the annual average price of cement in a region. CONSTRUCTION INV. is the logarithm of the sum of private and government construction investments. HOKKAIDO, KINKI, SHIKOKU, TOHOKU and TOKAI are market fixed effects (relative to the Chugoku region).

\begin{tabular}{lcc}
\hline \hline Variables & Coef. & Std. err. \\
& & \\
PRICE & -1.309 & 0.719 \\
CONSTRUCTION INV. & 1.636 & 0.217 \\
HOKKAIDO & -0.392 & 0.058 \\
KINKI & 0.595 & 0.068 \\
SHIKOKU & -0.362 & 0.038 \\
TOHOKU & 0.195 & 0.043 \\
TOKAI & 0.430 & 0.089 \\
CONST. & -1.776 & 3.844 \\
& & \\
Adj.R square $=0.9737$ & & \\
No.obs. $=54$ & & \\
& & \\
\hline
\end{tabular}

Table 6: Estimates of Cost Function Parameters NO.SS is the number of firms' SSs in a region (in logarithm). HOKKAIDO, KINKI, SHIKOKU, TOHOKU and TOKAI are market fixed effects (relative to the Chugoku region).

\begin{tabular}{lcc}
\hline \hline Variables & Coef. & Std. err. \\
NO.SS & -0.1885 & 0.0148 \\
HOKKAIDO & -0.0481 & 0.0142 \\
KINKI & 0.0569 & 0.0141 \\
SHIKOKU & 0.0232 & 0.0141 \\
TOHOKU & -0.1744 & 0.0149 \\
TOKAI & -0.1334 & 0.0056 \\
CONST. & 9.2433 & 0.0152 \\
& & \\
Adj.R square $=0.778$ & & \\
No.obs. $=261$ & & \\
& & \\
\hline
\end{tabular}


Table 7: Cournot Model Quantity Prediction

The predicted quantity is computed using the estimated parameters of the demand and cost functions.

\begin{tabular}{lrr}
\hline \hline & & \\
Quantile & Predicted & Observed \\
$10 \%$ & 95083.9 & 168271 \\
$20 \%$ & 408598.7 & 233807.9 \\
$30 \%$ & 629789.7 & 460621.4 \\
$40 \%$ & 755262.0 & 649979.8 \\
$50 \%$ & 958510.2 & 805400 \\
$60 \%$ & 1153626.2 & 1148229.4 \\
$70 \%$ & 1377622.1 & 1483176 \\
$80 \%$ & 1892844.1 & 1966102.6 \\
$90 \%$ & 2372639.8 & 2392681.4 \\
& & \\
Mean & 1071552.972 & 1034252.167 \\
Std. dev. & 850884.1383 & 808382.7203 \\
Corr. & 0.9563 & \\
& & \\
\hline
\end{tabular}

Table 8: Estimates of Policy Function

NO.SS is the number of firms' own SSs. COMPETITOR $j$ 's NO.SS is the number of competitor $j$ 's SSs, where $j=\{1,2,3,4\}$. The competitors are listed in descending order based on their number of SSs. CONSTRUCTION INV. is the logarithm of the sum of private and government construction investment. REGIONAL GDP is the logarithm of regional GDP. Market-specific effects are included but not reported.

\begin{tabular}{lcc}
\hline \hline Variables & Coef. & Std. err. \\
NO.SS & 0.3361241 & 0.0476029 \\
COMPETITOR 1's NO.SS & 0.2211487 & 0.0517786 \\
COMPETITOR 2's NO.SS & 0.0117523 & 0.1096288 \\
COMPETITOR 3's NO.SS & 0.0810625 & 0.1140884 \\
COMPETITOR 4's NO.SS & 0.2829826 & 0.3263801 \\
CONSTRUCTION INV. & -11.93407 & 3.078503 \\
REGIONAL GDP & 0.1834246 & 5.926712 \\
CONST. & 199.5817 & 105.4886 \\
& & \\
Log likelihood $=-106.2387$ & & \\
No.obs. $=261$ & & \\
& & \\
\hline
\end{tabular}


Table 9: Policy Function Prediction

\begin{tabular}{ccccc}
\hline \hline & & & & \\
DIVESTMENT & Normal & Logistic & Uniform & Data \\
0 & 77.3103 & 71.5249 & 70.272 & 78.93 \\
1 & 16.8046 & 16.5939 & 24.9885 & 13.41 \\
2 & 4.2414 & 6.9004 & 3.5517 & 4.21 \\
3 & 1.1762 & 3.2759 & 1.0996 & 2.68 \\
4 & 0.4674 & 1.705 & 0.0881 & 0.77 \\
& & & & \\
\hline
\end{tabular}

Table 10: Structural Parameter Estimates (million yen)

\begin{tabular}{crr}
\hline \hline & Mean & Std. err \\
& & \\
$\mu$ & 18.43 & 12.98 \\
$k$ & 2.85 & 0.51 \\
$f_{\text {ss }}$ & 113.52 & 41.08 \\
& & \\
\hline
\end{tabular}

Table 11: Sell-off Value Estimates and Land Values (million yen)

\begin{tabular}{lccc}
\hline \hline \multirow{2}{*}{ Region } & \multicolumn{2}{c}{ Estimated Values } & Land Values \\
& Mean $\left(\hat{\mu} \bar{v}_{r}\right)$ & Std. dev. $\left(\hat{k} \bar{v}_{r}\right)$ & {$[5 \%, 95 \%]$} \\
Hokkaido & 350 & 43 & {$[98.4,735]$} \\
Tohoku & 754 & 92 & {$[70.3,506]$} \\
Tokai & 1366 & 167 & {$[312,1330]$} \\
Kinki & 1426 & 174 & {$[228,1940]$} \\
Chugoku & 518 & 63 & {$[321,2111]$} \\
Shikoku & 246 & 30 & {$[97.9,422]$} \\
& & & \\
\hline
\end{tabular}


Table 12: Welfare Analysis (billion yen)

All values are the mean of 100 simulation paths, of 10 years' length. The starting state of the market without mergers is $\omega=(11,10,9,8,7,4,4, z, v)$, and that of the market with mergers is set at $\omega=(21,15,9,8, z, v)$. The starting demand shifter $z$ is the amount of construction investment in 1994 and is common to both markets. The mean of regional GDPs is used for $v$.

\begin{tabular}{lccc}
\hline \hline & & & \\
& $\mathrm{w} /$ Mergers & $\mathrm{w} / \mathrm{o}$ Mergers & Difference \\
CONSUMER SURPLUS & 1822.042 & 1847.517 & -25.4744 \\
PRODUCER SURPLUS & 86.93775 & 54.83691 & 32.10084 \\
FIXED COSTS & -42.875 & -49.6508 & 6.775784 \\
SELL-OFF VALUE & 17.95986 & 1.85906 & 16.1008 \\
TOTAL WELFARE & 1884.065 & 1854.562 & 29.50305 \\
& & & \\
\hline
\end{tabular}

